What Determines Price Changes and the Distribution of Prices? Evidence from the Swiss CPI

Reto Föllmi, Rudolf Minsch, Fabian Schnell

July 2016 Discussion Paper no. 2016-10

School of Economics and Political Science, Department of Economics 


$\begin{array}{ll}\text { Editor: } & \text { Martina Flockerzi } \\ & \text { University of St.Gallen } \\ & \text { School of Economics and Political Science } \\ & \text { Department of Economics } \\ & \text { Bodanstrasse } 8 \\ & \text { CH-9000 St. Gallen } \\ & \text { Phone } \quad+41712242325 \\ & \text { Fax } \quad+41712243135 \\ & \text { Email seps@unisg.ch } \\ & \text { School of Economics and Political Science } \\ & \text { Department of Economics } \\ & \text { University of St.Gallen } \\ & \text { Bodanstrasse } 8 \\ \text { Publisher: } & \text { CH-9000 St. Gallen } \\ & \text { Phone +41 71 224 23 25 } \\ & \text { Fax +41 71 224 31 35 } \\ & \text { http://www.seps.unisg.ch }\end{array}$




\title{
What Determines Price Changes and the Distribution of Prices? Evidence from the Swiss $\mathrm{CPI}^{1}$
}

\author{
Reto Föllmi, Rudolf Minsch, Fabian Schnell
}

Author's address:

\author{
Prof. Dr. Reto Föllmi \\ Swiss Institute for International Economics and Applied \\ Economic Research (SIAW-HSG) \\ Bodanstrasse 8 \\ $\mathrm{CH}-9000$ St. Gallen \\ Phone $\quad+41712242340$ \\ Fax $\quad+41712242298$ \\ Email_reto.foellmi@unisg.ch \\ Website www.siaw.unisg.ch \\ Prof. Dr. Rudolf Minsch \\ Email_rudolf.minsch@economiesuisse.ch \\ Dr. Fabian Schnell \\ Email fabian.schnell@unisg.ch
}

\footnotetext{
${ }^{1}$ The authors thank Martin Huber and Lukas Schmid, as well as the participants of the April 3, 2014, SinergiaSeminar at the University of Zurich, and the participants of the 2014 conference of the Swiss Society of Economics and Statistics in Bern for their helpful comments and suggestions. We are also very grateful to Hans-Markus Herren from the Swiss Federal Statistical Office, who provided us with the data. The views expressed in this paper are those of the authors and do not necessarily represent those of economiesuisse or Avenir Suisse.
} 


\begin{abstract}
This paper examines how firms set and adjust their prices, depending on macroeconomic, sectoral and individual conditions. A large panel of 345,963 observations of quarterly firm and product price data, underlying the Swiss sectoral CPIs from 1993 to 2012, is used for this purpose. The data allows us to trace the pricing decisions of the identified firm over time and in detail (without regular interruption of the price series as in the case of the US CPI). Among several macroeconomic factors, the appreciation of the Swiss franc results in an increase in the probability of a positive price change and, to a lesser extent, in the size of price changes. Singling out one policy measure, we found that an increase in the VAT is over-proportionally shifted to prices by firms who change their prices. Finally, the data set allows for the analysis of the development of price dispersion at the product level. We can demonstrate that an increase in the VAT led to a decrease in the variance in prices, whereas macroeconomic factors have no impact.
\end{abstract}

\title{
Keywords
}

Price Setting Behavior of Firms, Frequency of Price Changes, Price Dispersion.

\section{JEL Classification}

E31, E37, E52. 


\section{Introduction}

The price setting behavior of firms is central to understanding macroeconomic policies. Price stickiness is well documented in the empirical literature (e.g., Bils and Klenow (2004), Álvarez et al. (2006)). However, most papers focus on the frequency of price adjustments, i.e., the extensive margin, without studying the sizes of price changes. In contrast, there is little available knowledge on the intensive margin, i.e., the extent to which a firm adjusts its prices and what determines the size of a price change. The same lack of knowledge is true for price setting vis-à-vis competitors, i.e., for the distribution of prices over time.

This paper attempts to fill these two gaps by using a panel data set of specific product prices underlying several Swiss sectoral CPI data series. The sectors are typical nontradable services, i.e., cinemas, hairdressers and restaurants (food and drinks). The advantage of this data set is that it allows an apportionment of each data point to a specific firm, sector or product group, and does not rely on a qualitative survey. A unique feature compared to other datasets is that the price series of individual firms do not interrupt on a regular basis as this is the case, for example, for US CPI data. ${ }^{1}$ This enables us to estimate the average level and the dispersion of the entire price distribution. Consequently, we can look at many theoretically relevant state-dependent factors for pricing decision as well, in particular the relative position of the firm's price to the average price in the market.

We investigate the observable factors that influence price setting behavior at both the extensive and intensive margins, i.e., the frequency and the (average) size of price changes. Following the literature, we distinguish between time-dependent and statedependent variables, while a particular focus lay in the impact of the macroeconomic environment. In agreement with previous results (see the following section), we find that time-dependent variables are of less importance, with the exception of seasonality components, i.e., we can observe not only more but also, on average, stronger price adjustments during the first quarter of a year. State-dependent factors are of greater importance. The position of the firm's price relative to the average of its competitors is particularly relevant. We find that not only the probability but also the size of a price change increase to a greater extent the further a price is from the average price of the product.

Among several policy parameters, we study the impact of changes in the value-added tax (VAT), addressing how this external cost shock or its anticipation are reflected in prices. During the observed period, Switzerland experienced four increases in the VAT. Changes in the VAT, compared to other tax changes or policy measures, are particularly applicable to study because they can be considered as completely exogenous because Switzerland does not use this tax as an instrument of economic policy. Our results

${ }^{1}$ cp. Klenow and Kryvtsov (2008). 
indicate that firms who change their prices raise their prices more than the VAT increase, controlling for other factors, while the firms' costs increase only proportionally with the rise in the VAT. Thus, firms appear to regard a change in the VAT as an opportunity to increase their markups.

Finally, the phenomenon of price dispersion is gaining interest in macroeconomics as producer heterogeneity has become increasingly important. Our results indicate that an increase in the VAT led to a decrease in the variance in prices. This may stem therefrom that firms with a low price, relative to their competitors, adjust their prices upward when the VAT increases. Macroeconomic factors, however, do not appear to play a role, whereas other moments (i.e., skewness and kurtosis) are not influenced by the VAT.

The remainder of the paper is organized as follows. Section 2 provides a review of the relevant literature. Section 3 describes the data and provides descriptive statistics. Section 4 presents the results of the econometric estimations regarding the price setting behavior, whereas section 5 reports on the analysis of the development of price dispersion. Finally, section 6 concludes the paper.

\section{Review of related literature}

There are several theoretical models explaining the (not perfectly flexible) price setting behavior of firms from a macroeconomic perspective. Two branches can be identified. On the one hand, time-dependent models consider the timing of price changes as exogenously given, meaning that only the size of the price change is chosen by the respective firm. The most cited and widely employed approach has been developed by Calvo (1983) and implies that a specific firm can adjust its price in each period with a given, constant probability. A similar earlier model, developed by Taylor (1980), considers the length of contracts as fixed and postulates that prices can only be changed at the beginning of a contract. $^{2}$ Other models, such as the sticky information approach developed by Mankiw and Reis (2002), retains the central hypothesis of time-dependent price setting behavior by firms. On the other hand, state-dependent pricing, generally referred to as menu cost models, assumes that firms react to idiosyncratic shocks, i.e., that firms' pricing decisions are made independent of timing (Dotsey et al., 1999; Gertler and Leahy, 2008; Golosov and Lucas, 2007). A popular approach following this view is proposed by Rotemberg (1982), who models price changes as costly actions while costs increase disproportionally with the sizes of price changes. A newer approach following the same main idea is the rational inattention model developed by Maćkowiak and Wiederholt (2009), which assumes that firms decide what to pay attention to, which is a constrained action. Thus, firms cannot adjust prices fully flexibly, because they do not consistently possess all the necessary information.

${ }^{2}$ See also Taylor (1979) for the case of wage contracts. 
Most empirical research focuses on the frequency of price adjustments and their determinants and devotes less attention to the sizes of price changes. On the one hand, this lack of attention is a direct consequence of most theoretical models also tending to concentrate on frequency (as a measure of price stickiness). On the other hand, this lack might also be the result of limited data availability. Cecchetti (1986) uses data on the newsstand prices of American magazines to find a relationship between inflation and the frequency of price adjustments, a finding that is also supported by other authors. However, Cecchetti (1986) only concentrates on a single product. A broader set of data, i.e., twelve selected retail goods, is therefore considered by Kashyap (1995), who states that prices are normally fixed for more than one year; however, he also clearly emphasizes that the time between price changes is irregular, i.e., there is likely no stable frequency. It is therefore unsurprising that other papers report different frequencies. Bils and Klenow (2004), for example, who considers more than 350 categories of consumer goods, examines a frequency of approximately five months. Nakamura and Steinsson (2008) propose that $9-12 \%$ of prices change every month, but the price adjustments are highly seasonal, i.e., most prices change at the beginning of a year.

There is a small literature concerned with state-dependent pricing. Lein (2010) uses a survey across industrial firms in Switzerland where state-dependent variables are empirically important. Her data set also allows her to consider the impact of individual cost structures and expectations but not the sizes of price changes. Kaufmann (2009) considers a very similar data set to ours and for a broader set of subindices; however, his contribution remains descriptive. Honoré et al. (2012) also use data from subindices of the Swiss CPI to investigate the contribution of general inflation to the share of positive price changes in Switzerland. ${ }^{3}$

As mentioned above, little is empirically understood about the factors impacting the sizes of price adjustments. An exemption is the seminal work of Klenow and Kryvtsov (2008). These authors use item-based pricing for three sub-areas of the US CPI, suggesting that the frequency and size of price adjustments are unrelated to the timing. However, they do not discuss the size of the impact of macroeconomic fluctuations or developments. Our Swiss CPI data allow to estimate with reasonable precision the average and the dispersion of prices in a sector, since firms stay for a long time in our sample. This allows us to consider a broader set of state-dependent variables such as the relative price level of a firm vis-à-vis its competitors. In addition and again different to Klenow and Kryvtsov (2008),we study the pricing impact of macroeconomic fluctuations as well.

Regarding price dispersion, the existing empirical literature only focuses on very small industries, brief periods, or price dispersion across countries. Borenstein and Rose (1994), for example, examine the airline industry in 1986 and found greater dispersion

\footnotetext{
${ }^{3}$ Certain studies investigate the reaction of sectoral price indices (instead of prices in a narrow sense) to macroeconomic disturbances, e.g., Boivin et al. (2009), Maćkowiak et al. (2009), Kaufmann and Lein (2013), and Altissimo et al. (2009).
} 
on routes with more competition. ${ }^{4}$ Sorensen (2000) analyzes the distribution of prices charged by different pharmacies for several drugs. Clay et al. (2001) investigate the effects of advertising and branding on the differentiation of prices between online bookstores, and they observe a positive impact. Kaplan and Menzio (2014) follow a more general approach and investigate the shape and structure of the distribution of prices at which an identical good is sold. They find that the typical price distribution is symmetric. However, an earlier work by Lach and Tsiddon (1992) on the prices of food in Israel indicates that, with higher inflation, the price distribution of a given product becomes more right skewed.

A comparison of the general price levels among EMU countries is performed by Hoeberichts and Stokman (2011), finding that the dispersion of price levels is negatively related to business cycles. Contrary to existing work, our data set allows us to observe price dispersions for many products over a relatively long period.

\section{Data description and descriptive statistics}

\subsection{The data}

Our analysis is based on a set of panel data on the underlying subindices of the Swiss CPI. The data are provided by the Swiss Federal Office of Statistics (SFOS). The data set allows us to track the development of a single price for a given product charged by a given firm over time. Data are available for four subindices of the Swiss CPI: hairdressers, cinemas, food in restaurants, and drinks in restaurants, representing a total weight of $4.13 \%$ in the Swiss CPI in 2013. These four available sectors all represent classical non-tradable services. ${ }^{5}$

The data appear on a quarterly basis from 1993Q2 to 2012Q4. Firms and products enter and exit the data set on an irregular basis, but these changes are documented. ${ }^{6}$ Thus, a few prices can be tracked over the entire sample, which is a central advantage of the data set over others (e.g., Klenow and Kryvtsov (2008), in which products always drop out the data set after at most five years). Furthermore, only $0.21 \%$ of all the recorded price changes in the data set are due to temporary sales, which largely eliminate a critical source of disturbances in the estimation. A disadvantage of the data is that we could not observe any additional information about the tracked firms, i.e., we do not know anything about the location or firm size.

\footnotetext{
${ }^{4}$ Sengupta and Wiggins (2014) extend this line of analysis by accounting for online purchases of airline fares. They do not observe reduced dispersion following increased online shopping.

${ }^{5}$ Note that detailed price data underlying the Swiss CPI are normally confidential and unavailable, which is why data on additional sectors are not available.

${ }^{6}$ Further, the total number of recorded prices varies over time. On average, a firm remains for 35.33 periods and a single product for 21.74 periods in the sample.
} 
In the second quarter of 2000, we observe a disproportionately large number of firms and products that are replaced, because the method for calculating the CPI in Switzerland changed at this point in time. ${ }^{7}$ A limited number of substantial price jumps indicate potential measurement errors at this time; however, we retain these observations in the data because they have little impact on the results.

The data set records, based on the statistical criteria of the SFOS, whether a certain product is replaced by a new one, e.g., because of a substantial quality improvement. If we observe such a replacement, we consider the given price series as terminated and begin a new one. Using this procedure, we have a total of 15,932 price series consisting of 73 different products. Overall, the data comprises 345,963 observations representing an unbalanced panel structure.

Table 1 provides an overview of the data structure. Note that the total number of observations refers to the number of observed prices and not to the number of price changes.

Table 1: Overview data.

\begin{tabular}{lc}
\hline \hline Specification & Number \\
\hline Producers (or firms), $j$ & 457 \\
Product groups, $\Omega$ & 4 \\
Products, $i$ & 73 \\
Price series, $p\left(i_{n}, j\right)$ & 15,932 \\
Quarters, $t$ & 79 \\
Observations, $p\left(i_{n}, j, t\right)$ & 345,963 \\
\hline Time span & 1993Q2-2012Q4 \\
\hline \hline
\end{tabular}

\subsection{Constructed variables}

Three variables are constructed from the data. The first reflects, at each point in time and for each price series, the number of periods since the last non-zero price change. Let $p\left(i_{n}, j, t\right)$ be the price of product $i_{n}$ (where $n$ is the number of the product, if the same product type, $i$, is sold more than once by the same firm), charged by firm $j$ in period $t$; then, $\hat{p}\left(i_{n}, j, t\right):=\frac{p\left(i_{n}, j, t\right)-p\left(i_{n}, j, t-1\right)}{p\left(i_{n}, j, t-1\right)}$ subsequently defines the respective relative change in this price. Furthermore, we denote $k_{1}\left(i_{n}, j\right), k_{2}\left(i_{n}, j\right), \ldots, k_{m}\left(i_{n}, j\right), \ldots, k_{M}\left(i_{n}, j\right)$ as those periods during which we observe a change in the price, $p\left(i_{n}, j, t\right)$. In formal terms:

$$
t= \begin{cases}k_{m}\left(i_{n}, j\right), & \text { if } \hat{p}\left(i_{n}, j, t\right) \neq 0 \\ k_{m}\left(i_{n}, j\right)+z\left(i_{n}, j, t\right), & \text { otherwise }\end{cases}
$$

where $z\left(i_{n}, j, t,\right):=\min _{k_{m}\left(i_{n}, j\right)<t}\left(t-k_{m}\left(i_{n}, j\right)\right) \forall t, m$ therefore represents the desired number of periods since the last price change. In constructing the variable $z\left(i_{n}, j, t,\right)$,

\footnotetext{
${ }^{7}$ See Kaufmann (2009) for a broader discussion.
} 
we were forced to omit the data before the first price change in every price series, i.e., all data points at $t<k_{1}\left(i_{n}, j\right)$. This procedure follows Klenow and Kryvtsov (2008), who also note that the estimations would be biased otherwise.

Second, we are interested in the accumulated sectoral inflation after a price change as a measurement of the general development of prices. Each product, $i$, belongs to one of the four Swiss CPI subindices considered, which we denote as $\Omega .{ }^{8} \mathrm{CPI}_{\Omega(i)}(t)$ therefore represents the subindex to which product $i$ belongs (in period $t$ ). Given this notation, the inflation accumulated since the last price change, denoted $\pi\left(i_{n}, j, t\right)$, is defined as follows:

$$
\pi\left(i_{n}, j, t\right):=\min _{k_{m}\left(i_{n}, j\right)<t} \frac{\mathrm{CPI}_{\Omega(i)}(t-1)-\mathrm{CPI}_{\Omega(i)}\left(k_{m}\left(i_{n}, j\right)\right)}{\operatorname{CPI}_{\Omega(i)}\left(k_{m}\left(i_{n}, j\right)\right)} .
$$

Note that equation (2) implies that accumulated inflation is measured as the inflation occurring between the last price change and period $t-1$, which is assumed for the following reason: A firm that is deciding whether it wishes to change one of its prices in period $t$ only knows the inflation rate prior to period $t-1$, because the inflation rate of period $t$ remains unknown until all the firms have made their pricing decisions in period $t$. Moreover, the construction of the variable also prevents a potential endogeneity problem.

Third and as a particular feature of our dataset, we are able to calculate each price relative to the mean price of its product category, $i$, at each point in time, $t$. For this purpose, we define $A(i, t):=\sum_{n, j} 1_{t}\left[p\left(i_{n}, j, t\right)\right]$ as the total (unweighted) number of observed prices of product $i$ in period $t$. Thus, $1_{t}[$.$] is an indicator function taking a value equal$ to one if $p\left(i_{n}, j, t\right)>0$ in period $t$ and zero otherwise. Denoting the individual deviation from the mean price as $\rho\left(i_{n}, j, t\right)$, we can define

$$
\rho\left(i_{n}, j, t\right):=\frac{p\left(i_{n}, j, t\right)}{\frac{1}{A(i, t)} \sum_{n, j} p\left(i_{n}, j, t\right)}-1 .
$$

Note that, by construction, it holds that $\frac{1}{A(i, t)} \sum_{n, j} \rho\left(i_{n}, j, t\right)=0 \forall i, t$. The variable $\rho\left(i_{n}, j, t\right)$ provides us with a measurement of the competitive standing of the respective price. It is clear that this measurement is only an approximation, because we cannot observe other important factors, such as distance to the nearest competitor or other cost factors.

\subsection{Descriptive statistics}

Table 2 presents the frequency of price changes (positive and negative) disaggregated by each individual product sector, $\Omega$. In the full sample, the prices are changed in $9 \%$ of all the observations. Compared to the literature, the firms in our data set change prices

${ }^{8}$ Data on the Swiss CPI subindices are provided by the SFOS. 
relatively infrequently. Lein (2010), for example, report values for Swiss manufacturers that are three times higher. The reason for this difference may lie in the different set of products (non-tradable services) that our data set contains.

Table 2: Share of price changes.

\begin{tabular}{lccccc}
\hline \hline Product sector, $\Omega$ & Cinema & Hairdresser & $\begin{array}{c}\text { Rest., } \\
\text { drinks }\end{array}$ & $\begin{array}{c}\text { Rest., } \\
\text { food }\end{array}$ & Total \\
Price change (abs.) & $6.0 \%$ & $8.9 \%$ & $9.4 \%$ & $9.1 \%$ & $\mathbf{9 . 1 \%}$ \\
Pos. price change & $5.1 \%$ & $8.4 \%$ & $8.2 \%$ & $7.4 \%$ & $\mathbf{7 . 8 \%}$ \\
Neg. price change & $0.9 \%$ & $0.5 \%$ & $1.2 \%$ & $1.7 \%$ & $\mathbf{1 . 3 \%}$ \\
\hline Numb. of observations & 12,870 & 42,104 & 132,140 & 142,893 & $\mathbf{3 3 0 , 0 0 7}$ \\
Numb. of firms in total & 67 & 198 & 189 & 188 & $\mathbf{4 5 7}$ \\
\hline \hline
\end{tabular}

The data also suggest strong downward price rigidity, in line with the findings provided by Kaufmann (2009), which can to some extent be explained by the nominal downward rigidity of wages, as described by Fehr and Goette (2005) for the case of Switzerland.

Figure 1 graphically illustrates the (unweighted) frequency of price changes over time, measured as a share of all the observations in each quarter. The graph provides two main insights. First, the peaks in the first quarters of 1995 and 1999 and, to a lesser extent, in the first quarters of 2001 and 2012 reflect the increases in the VAT that occurred at these times. In the first quarter of 1995, when the VAT was introduced, $75.5 \%$ of all of the prices in the sample were changed. ${ }^{9}$ Second, the graph indicates that the frequency of price changes is seasonal, with a peak in the first quarter of the year and a decrease thereafter.

\footnotetext{
${ }^{9}$ Note that the service sector in Switzerland was not required to pay any sales or value-added taxes before this point in time.
} 


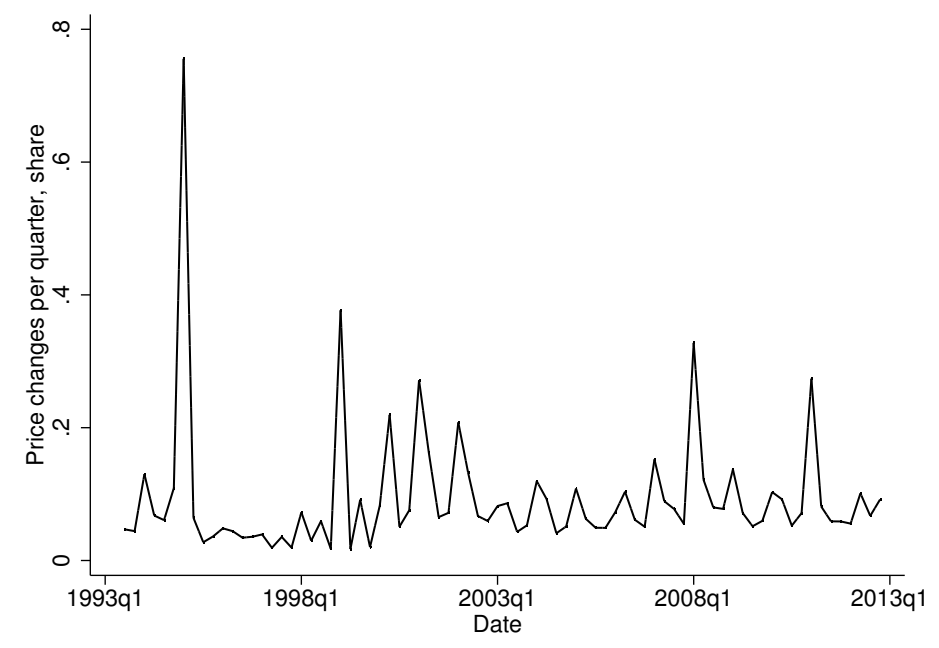

Figure 1: Frequency of price changes, on a quarterly basis. Notes: Price changes related to sales are excluded.

The seasonality of the frequency of price changes is also supported when examining the distribution of time periods between price changes, $z\left(i_{n}, j, t\right.$, ), as illustrated in figure 2. As with most models, the distribution is right skewed, i.e., the more time that has passed since the last price change, the greater the probability is that a firm will adjust its prices. However, we can also observe a local peak in every fourth period, indicating the above-mentioned concentration of price changes during the first quarter of the year.

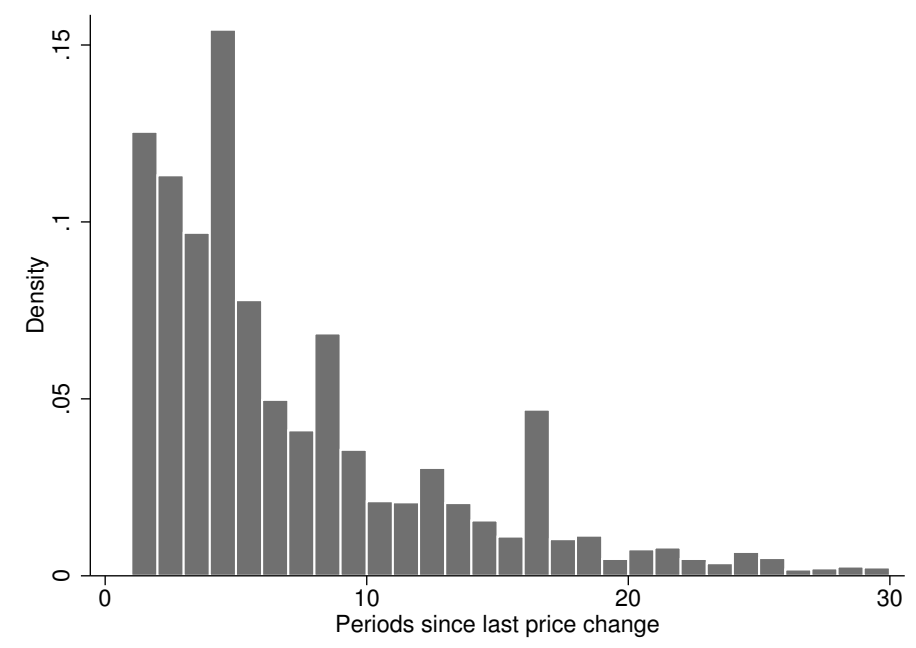

Figure 2: Distribution of times between price changes, $z\left(i_{n}, j, t,\right)$. Notes: Price changes related to sales are excluded. 
Contrary to many other datasets, we are able to calculate not only the frequency but also the size of price changes. Table 3 and figure 3 describe how the size of non-zero price changes are distributed. For this purpose, we normalize the data in the sense that we subtract the accumulated sectoral inflation at every non-zero price change (data points without a price change, constituting the majority, are excluded), i.e., the statistics refer to data of the following form:

$$
\hat{p}_{\text {norm }}\left(i_{n}, j, t\right):=\left\{\begin{array}{ll}
\hat{p}\left(i_{n}, j, t\right)-\pi\left(i_{n}, j, t\right), & \text { if } \hat{p}\left(i_{n}, j, t\right) \neq 0 \\
\emptyset, & \text { otherwise }
\end{array} .\right.
$$

The normalization allows us to interpret the size of a price change while abstracting from the potential "distortion" of the general price development. Consequently, the average normalized price change is therefore not statistically different from zero. We can observe a relatively broad distribution of price changes, implying that other factors might also be important in the price setting process. However, the distribution is right skewed, providing some evidence for the potential real downward rigidity of price setting.

Table 3: Statistics for relative price changes corrected by sectoral inflation, $\hat{p}_{n o r m}\left(i_{n}, j, t\right)$.

\begin{tabular}{ccccc}
\hline \hline & Mean & St.Dev. & Min. & Max. \\
Normalized price change, $\hat{p}_{\text {norm }}\left(i_{n}, j, t\right)$ & $0.147 \%$ & $2.243 \%$ & $-79.86 \%$ & $193.2 \%$ \\
\hline \hline
\end{tabular}

Notes: Price changes related to sales are excluded.

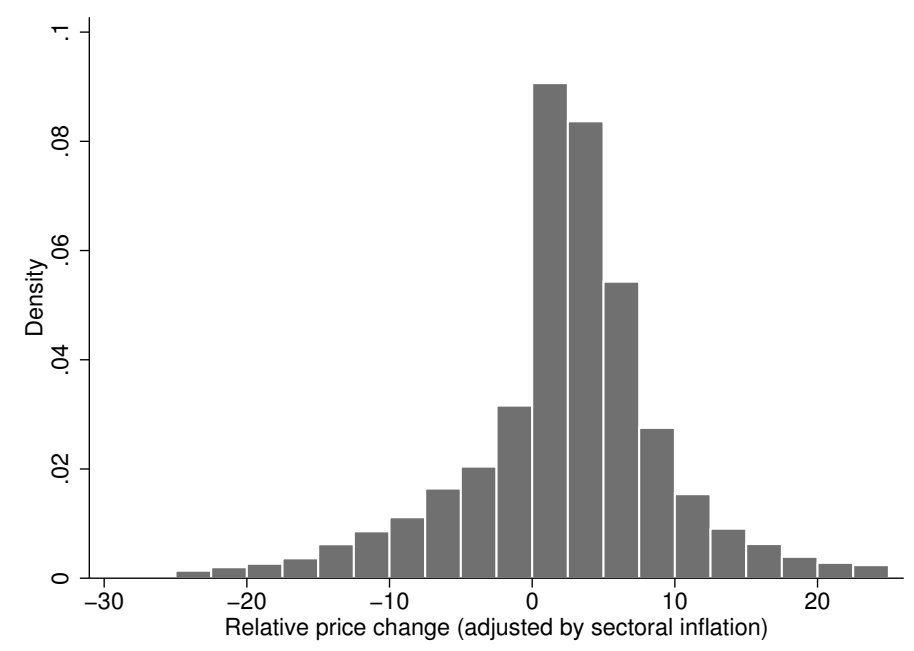

Figure 3: Histogram of relative price changes corrected by sectoral inflation, $\hat{p}_{n o r m}\left(i_{n}, j, t\right)$. Notes: Price changes related to sales are excluded. 


\section{Econometric results}

\subsection{Methodology}

Two types of estimations are conducted in this section. First, we focus on the extensive margin, i.e., we estimate how the different factors influence the probability of a (positive or negative) price change. A conditional logit model is employed for this purpose. The conditional form is appropriate because we are unable to observe any individual attributes of firms or price series within the data set. In the second part, we focus on the intensive margin, i.e., we estimate how the various factors influence the sizes of price adjustments on average (i.e., we also consider the data points with no price changes because these represent also pricing decisions) by relying on a standard OLS framework.

In each of the two models, we estimate three regression specifications, but the specifications differ in the numbers of variables included. The first specification is estimated by using only time-dependent variables and the variables concerning the VAT, as a specific and important policy measure. ${ }^{10}$ The time-dependent variables consist of the number of periods between two price changes, $z\left(i_{n}, j, t\right)$, as well as dummies for the first, second and third quarters of each year.

The variables concerning the VAT are of three types. One reports the relative change in the VAT in the quarter when this change occurs. ${ }^{11}$ The second group of VAT variables simply consists of the first two lags of the first variable. The third type of variable consists of the relative change in the VAT at the points in time when this change is officially known to occur in some number of quarters in the future and is zero otherwise. For the case of Switzerland, this condition means that a change in the VAT is approved through a popular vote or the deadline for a referendum against an increase in the VAT has passed. The VAT increases in 1995 and 2001 were therefore known four quarters before they were enacted. The VAT increases in 1999 and 2012 were known three and five quarters in advance, respectively.

The second specification adds the accumulated sectoral inflation, $\pi\left(i_{n}, j, t\right)$, and the relative deviation from the mean price, $\rho\left(i_{n}, j, t-1\right)$, as proxies for price-series-specific state variables. ${ }^{12}$ Finally, the third specification includes variables for the macroeconomic environment. These variables are real year-on-year GDP growth, the quarter-on-quarter growth rate of the real exchange rate index, and the first difference in the three-month LIBOR interest rate. ${ }^{13}$ All the macroeconomic variables add up to a lag of four quarters. $^{14}$

\footnotetext{
${ }^{10}$ See also Kaufmann (2009) who observe a significant impact of of the VAT at the aggregated level.

${ }^{11}$ The relative change in the VAT, denoted $\tau_{t}$ (for period $t$ ), is determined as follows: $\frac{1+\tau_{t}}{1+\tau_{t-1}}-1$.

${ }^{12}$ To capture the effect on the actual pricing decision, the latter is measured in the pre-period.

${ }^{13}$ Data on the real GDP growth are provided by the SFOS. Data on the real exchange rate index and the LIOBR are provided by the Swiss National Bank. Note that the use of the exchange rate relative to the euro, instead of the real exchange rate index, affects the results only slightly.

${ }^{14}$ One might argue that future expectations of these variables might also play roles. However, the use of lags can be considered a reduced form, because expectations are also functions of past realizations.
} 
A dummy for the second quarter of 2000 is also included in each estimation, and the same holds for starting and ending points of temporary sales. ${ }^{15}$ All the estimations also include product-series-specific fixed effects to control for series-specific shocks. Because the firm is the relevant pricing decision unit, standard errors are clustered at the firm level, as proposed by Lein (2010).

\subsection{Pricing at the extensive margin}

This section analyzes the factors that influence individual pricing decisions at the extensive margin (i.e., whether a firm changes its price), using a conditional logit probability model. The estimations for the three specifications are performed twice: once for positive price changes and once for negative price changes. All the tables report marginal effects evaluated at the variables' means, given no price-series-specific shocks. For the dummy variables, the marginal effects are calculated at the change of the dummy from 0 to 1.

Table 4 presents the results of the estimations, which are generally in line with the literature regarding the role of the number of periods since the last price change and the confirmation of the descriptive evidence that most price changes occur in the first quarter of a year, i.e., seasonality is the most important time-dependent factor. The respective coefficient is highly significant in all estimations and specifications.

Table 4: Cond. logit probability model.

\begin{tabular}{lccc}
\hline \hline Panel A: Positive price changes & Specification 1 & Specification 2 & Specification 3 \\
\hline Rel. change VAT & $0.709^{* * *}$ & $0.737^{* * *}$ & $0.611^{* * *}$ \\
Rel.chan. VAT, 1 Lag(s) & $(0.047)$ & $(0.055)$ & $(0.055)$ \\
& 0.037 & 0.004 & -0.069 \\
Rel.chan. VAT, 2 Lag(s) & $(0.055)$ & $(0.052)$ & $(0.056)$ \\
Fut.VAT-incr. known, 1 Lag(s) & 0.017 & -0.010 & -0.092 \\
& $(0.058)$ & $(0.058)$ & $(0.064)$ \\
Fut.VAT-incr. known, $2 \operatorname{Lag}(\mathrm{s})$ & $0.249^{* * *}$ & $0.244^{* * *}$ & $0.234^{* * *}$ \\
& $(0.053)$ & $(0.051)$ & $(0.057)$ \\
Fut.VAT-incr. known, $3 \operatorname{Lag}(\mathrm{s})$ & $0.180^{* * *}$ & $0.177^{* * *}$ & $0.235^{* * *}$ \\
& $(0.061)$ & $(0.060)$ & $(0.058)$ \\
Fut.VAT-incr. known, $4 \mathrm{Lag}(\mathrm{s})$ & -0.068 & -0.055 & 0.093 \\
& $(0.106)$ & $(0.092)$ & $(0.070)$ \\
Fut.VAT-incr. known, 5 Lag(s) & 0.004 & -0.024 & 0.040 \\
Periods since last price change, $z\left(i_{n}, j, t,\right)$ & $(0.070)$ & $(0.072)$ & $(0.063)$ \\
& 0.158 & -0.035 & 0.220 \\
$z\left(i_{n}, j, t,\right)^{2}$ & $(0.603)$ & $(0.601)$ & $(1.054)$ \\
& $0.125^{* * *}$ & $0.091^{* * *}$ & $0.081^{* * *}$ \\
Dummy 1st quarter & $(0.011)$ & $(0.014)$ & $(0.014)$ \\
& $-0.001^{* * *}$ & $-0.002^{* * *}$ & $-0.002^{* * *}$
\end{tabular}

\footnotetext{
${ }^{15}$ The dummy for the second quarter of 2000 is included because of the relatively high proportion of product replacements during this period due to a change in the method for calculating the CPI. See section 3.1 .
} 
Dummy 2nd quarter

Dummy 3rd quarter

Sales

Sales end

Dummy 2000Q2

Acc.sec.infl., $\pi\left(i_{n}, j, t\right)$

Price relative to mean price, $\rho\left(i_{n}, j, t-1\right)$

$\rho\left(i_{n}, j, t-1\right)^{2}$

GDP growth, yoy

Lag 1 quarters

Lag 2 quarters

Lag 3 quarters

Lag 4 quarters

RER index, gr. qoq

Lag 1 quarters

Lag 2 quarters

Lag 3 quarters

Lag 4 quarters

Lag 1 quarters

Lag 2 quarters

Lag 3 quarters

Lag 4 quarters

Lag 4 quarters 3m LIBOR, 1st diff.

$0.596^{* * *}$
$(0.100)$
0.111
$(0.086)$
$-14.623^{* * *}$
$(0.493)$
$3.225^{* * *}$
$(0.536)$
$0.871^{* * *}$
$(0.148)$

$0.573^{* *}$

(0.099)

0.099

(0.086)

$-13.892^{* * *}$

(0.526)

$2.770^{* * *}$

(0.484)

$1.052^{* * *}$

(0.154)

$0.096^{* * *}$

(0.035)

$-0.072^{* * *}$

$(0.005)$

$0.001^{* *}$

(0.000)

$0.580^{* * *}$

(0.117)

$0.229^{* *}$

(0.094)

$-13.718^{* * *}$

(0.467)

$2.865^{* * *}$

(0.458)

$1.246^{* * *}$

(0.200)

$0.140^{* * *}$

(0.036)

$-0.073^{* * *}$

(0.005)

$0.001^{* *}$

(0.000)

0.028

(0.042)

$-0.028$

(0.067)

$-0.006$

(0.068)

$-0.150^{* *}$

(0.064)

$0.255^{* * *}$

(0.037)

$0.099^{* * *}$

(0.015)

$0.101^{* * *}$

(0.019)

0.014

(0.019)

$-0.044^{* * *}$

(0.017)

$-0.025$

(0.018)

$-0.069$

(0.106)

$-0.098$

(0.110)

$0.382^{* * *}$

(0.096)

0.082

(0.126)

0.136

(0.095)

\begin{tabular}{lccc}
\hline Pseudo $R^{2}$ & & & \\
Observations & 180,032 & 0.186 & 0.208 \\
\hline \hline Panel B: Negative price changes & Specification 1 & Specification 2 & Specification 3 \\
\hline Rel. change VAT & -0.032 & $-0.091^{*}$ & $-0.142^{* *}$ \\
& $(0.047)$ & $(0.047)$ & $(0.062)$ \\
Rel.chan. VAT, 1 Lag(s) & $-0.223^{* * *}$ & $-0.265^{* * *}$ & $-0.299^{* * *}$ \\
& $(0.068)$ & $(0.072)$ & $(0.076)$ \\
Rel.chan. VAT, 2 Lag(s) & -0.093 & $-0.135^{* *}$ & $-0.174^{* * *}$ \\
& $(0.058)$ & $(0.058)$ & $(0.065)$ \\
Fut.VAT-incr. known, 1 Lag(s) & -0.002 & -0.070 & $-0.099^{*}$ \\
& $(0.045)$ & $(0.051)$ & $(0.059)$ \\
Fut.VAT-incr. known, 2 Lag(s) & -0.058 & $-0.139^{* *}$ & $-0.177^{* * *}$ \\
& $(0.060)$ & $(0.063)$ & $(0.066)$ \\
Fut.VAT-incr. known, 3 Lag(s) & 0.004 & -0.075 & $-0.117^{*}$
\end{tabular}


Fut.VAT-incr. known, 4 Lag(s)

Fut.VAT-incr. known, 5 Lag(s)

Periods since last price change, $z\left(i_{n}, j, t,\right)$

$z\left(i_{n}, j, t,\right)^{2}$

Dummy 1st quarter

Dummy 2nd quarter

Dummy 3rd quarter

Sales

Sales end

Dummy 2000Q2

Acc.sec.infl., $\pi\left(i_{n}, j, t\right)$

Price relative to mean price, $\rho\left(i_{n}, j, t-1\right)$

$\rho\left(i_{n}, j, t-1\right)^{2}$

GDP growth, yoy

Lag 1 quarters

Lag 2 quarters

Lag 3 quarters

Lag 4 quarters

RER index, gr. qoq

Lag 1 quarters

Lag 2 quarters

Lag 3 quarters

Lag 4 quarters

3m LIBOR, 1st diff.

Lag 1 quarters

Lag 2 quarters

Lag 3 quarters

Lag 4 quarters $\begin{array}{lll}(0.054) & (0.057) & (0.063)\end{array}$

$\begin{array}{lll}-0.132 & -0.229^{* *} & -0.248^{* *}\end{array}$

$\begin{array}{lll}(0.108) & (0.113) & (0.122)\end{array}$

$\begin{array}{lll}-0.185 & 0.078 & -0.873\end{array}$

$(0.744) \quad(0.762)$

$\begin{array}{lll}-0.014 & 0.028 & 0.026\end{array}$

$\begin{array}{lll}(0.019) & (0.026) & (0.026)\end{array}$

$0.001^{*} \quad 0.001^{* *} \quad 0.001^{* *}$

$(0.001) \quad(0.001) \quad(0.001)$

$0.285^{* *} \quad 0.264^{* *} \quad 0.260^{* *}$

$\begin{array}{lll}(0.111) & (0.112) & (0.116)\end{array}$

$0.156 \quad 0.189^{*} \quad 0.208^{* *}$

$\begin{array}{lll}(0.099) & (0.098) & (0.104)\end{array}$

$\begin{array}{lll}0.086 & 0.114 & 0.087\end{array}$

$(0.110) \quad(0.111) \quad(0.123)$

$18.924^{* * *} \quad 24.956^{* * *} \quad 23.915^{* * *}$

$\begin{array}{lll}(0.344) & (0.401) & (0.474)\end{array}$

$1.196 \quad 1.854^{*} \quad 1.834^{*}$

$(0.900) \quad(1.047)$

$2.042^{* * *} \quad 1.887^{* * *} \quad 1.413^{* * *}$

$\begin{array}{lll}(0.236) & (0.244) & (0.296)\end{array}$

$-0.010 \quad-0.009$

(0.046) (0.049)

$0.125^{* * *} \quad 0.126^{* * *}$

(0.009) (0.009)

$-0.001^{* * *} \quad-0.001^{* *}$

$(0.000) \quad(0.000)$

0.018

$(0.068)$

$-0.085$

(0.082)

0.052

(0.087)

$-0.074$

(0.088)

0.002

$(0.059)$

0.010

$(0.017)$

$0.033^{*}$

(0.020)

0.033

(0.021)

0.024

(0.021)

0.015

$(0.023)$

$0.294^{*}$

(0.164)

0.108

(0.131)

$0.297^{* *}$

(0.144)

0.009

(0.171)

0.131

(0.128)

0.120

71,300

Standard errors in parentheses 
${ }^{*} p<0.1,{ }^{* *} p<0.05, * * * p<0.01$

An increase in the VAT has a positive effect on the probability of a positive price change, while this effect is only significant at the time of the increase itself or for as many as two lags before. After a VAT increase, the coefficient becomes insignificant or even negative. Unsurprisingly, the probability of a negative price change decreases as the VAT increases.

State-dependent factors (i.e., $\pi\left(i_{n}, j, t\right)$ and $\left.\rho\left(i_{n}, j, t-1\right)\right)$ are indicated to be of distinct importance in the pricing decision, as well as compared to time-dependent factors, in keeping with the literature (e.g., Klenow and Kryvtsov (2008)). However, accumulated inflation, $\pi\left(i_{n}, j, t\right)$, is only significant in the estimation of positive price changes, whereas the relative deviation from the mean price always affects the extensive pricing decision. The influence seems to be even stronger with regard to negative price changes, in which the inclusion of the variable notably leads to a remarkable increase in the goodness of the fit.

With exception of the interest rate, which has also a positive impact on the probability of a negative price change, macroeconomic factors only play roles in the estimation of positive price changes. Whereas the effect of the business cycle is rather unclear, we can observe a positive impact of the real exchange rate index and a change in the interest rate. Both results are interesting, because an appreciation of the home currency and an increase in the interest rate are intended to lead to a decrease in the price level. Recall that our data set is based on non-tradable services, which are not generally directly influenced by movements in the exchange rate. However, an appreciation of the home currency results in a decrease in the prices of imported goods, indicating that households' available incomes increase. This effect likely leads to a greater demand for non-tradable services as they are represented in our data set. ${ }^{16}$ This increasing demand might be the reason for the positive impact of the real exchange rate index.

\subsection{Pricing at the intensive margin}

This section analyzes the pricing decisions of firms at the intensive margin. In this context, the intensive margin refers to the unconditional impact of our explanatory variables on the sizes of price changes. Thus, we perform OLS estimations, treating the size of price changes, $\hat{p}\left(i_{n}, j, t\right)$, as the dependent variable including data points with no price changes because these represent also relevant pricing decisions. Note that all the relative changes are expressed in percentages, allowing for a direct interpretation of the coefficients. Table 5 presents the results of the three specifications. To make an example for proper interpretation, assume a one percent increase in the VAT. The coefficient in

\footnotetext{
${ }^{16}$ In more technical terms: The income effect of an exchange rate fluctuation appears to dominate the substitution effect.
} 
the first specification thus imply that prices rise on average by $0.992 \%$ according to our data sample, i.e., that those firms which really adjust prices must do that by a stronger degree than the coefficient suggests.

Regarding the time-dependent variables, we observe that the number of periods since the last price change has a significant, but small, impact on the size of a current price change. We also observe that the size of price changes (not only the probability) is larger in the first quarter of a year than in others. The observation that seasonality also plays a role at the intensive margin might to some degree be connected to wage contracts typically being renewed at the beginning of a calendar year in Switzerland. ${ }^{17}$

State-dependent factors also play more important roles at the intensive margin; however, the price development within a sector is of limited importance. If at all, only a small share of the general price evolution seems to be considered in the pricing decision. A better indicator might be represented by the deviation from the mean price, $\rho\left(i_{n}, j, t-1\right)$. The further from the mean that a price is, the stronger its correction is. However, with a coefficient of approximately -0.09 , the impact is rather small in size, indicating that factors other than standing within the market (with regard to the price) play important roles. ${ }^{18}$

Contrary to the conditional logit model, we cannot discern a clear impact of the real exchange rate index when totaling the effects of all lags. An immediate positive effect is equalized after four lags. A possible interpretation might be that an immediate wealth effect becomes operative after a change in the exchange rate, which allows for an increase in prices. However, this effects fades and becomes dominated by a substitution effect after a few periods.

Furthermore, we observe evidence of pro-cyclical behavior in the size of price changes but with some lag. Finally, the interest rate has a (although small) negative impact on the average size of price changes. A F-test considering the sum of all coefficients as zero can be rejected. ${ }^{19}$

Table 5: Estimation results: Size of relative price change.

\begin{tabular}{lccc}
\hline \hline & Specification 1 & Specification 2 & Specification 3 \\
\hline Rel. change VAT & $0.992^{* * *}$ & $0.999^{* * *}$ & $0.982^{* * *}$ \\
& $(0.048)$ & $(0.047)$ & $(0.049)$ \\
Rel.chan. VAT, 1 Lag(s) & $0.039^{* * *}$ & $0.032^{* * *}$ & 0.010 \\
& $(0.012)$ & $(0.012)$ & $(0.017)$ \\
Rel.chan. VAT, 2 Lag(s) & $0.033^{* * *}$ & $0.024^{* * *}$ & 0.017 \\
& $(0.007)$ & $(0.008)$ & $(0.013)$ \\
Fut.VAT-incr. known, 1 Lag(s) & $0.082^{* *}$ & $0.092^{* * *}$ & $0.080^{* *}$ \\
& $(0.032)$ & $(0.031)$ & $(0.032)$
\end{tabular}

\footnotetext{
${ }^{17} \mathrm{cp}$. Fehr and Goette (2005).

${ }^{18}$ Note that we notably observe a positive coefficient on the squared variable, i.e., $\rho\left(i_{n}, j, t-1\right)^{2}$. However, this small effect, stating that the total impact is principally non-linear, never dominates the linear coefficient.

${ }^{19}$ The respective p-value is 0.036 .
} 
Fut.VAT-incr. known, 2 Lag(s)

Fut.VAT-incr. known, 3 Lag(s)

Fut.VAT-incr. known, 4 Lag(s)

Fut.VAT-incr. known, 5 Lag(s)

Periods since last price change, $z\left(i_{n}, j, t,\right)$

$z\left(i_{n}, j, t,\right)^{2}$

Dummy 1st quarter

Dummy 2nd quarter

Dummy 3rd quarter

Sales

Sales end

Dummy 2000Q2

Acc.sec.infl., $\pi\left(i_{n}, j, t\right)$

Price relative to mean price, $\rho\left(i_{n}, j, t-1\right)$

$\rho\left(i_{n}, j, t-1\right)^{2}$

GDP growth, yoy

Lag 1 quarters

Lag 2 quarters

Lag 3 quarters

Lag 4 quarters

RER index, gr. qoq

Lag 1 quarters

Lag 2 quarters

Lag 3 quarters

Lag 4 quarters

3m LIBOR, 1st diff.

Lag 1 quarters

Lag 2 quarters

Lag 3 quarters

Lag 4 quarters

Constant

\begin{tabular}{|c|c|c|}
\hline $0.041^{* * *}$ & $0.055^{* * *}$ & $0.084^{* * *}$ \\
\hline (0.015) & (0.015) & $\begin{array}{l}(0.017) \\
0.066^{* * *}\end{array}$ \\
\hline 0.000 & 0.012 & $0.066^{* * *}$ \\
\hline$(0.017)$ & $(0.017)$ & $(0.019)$ \\
\hline 0.011 & 0.003 & 0.014 \\
\hline$(0.027)$ & $(0.028)$ & $(0.029)$ \\
\hline-0.047 & -0.273 & -0.352 \\
\hline$(0.249)$ & $(0.238)$ & $(0.428)$ \\
\hline $0.046^{* * *}$ & $0.023^{* * *}$ & $0.016^{* * *}$ \\
\hline$(0.004)$ & $(0.005)$ & $(0.005)$ \\
\hline$-0.000^{* * *}$ & $-0.001^{* * *}$ & $-0.001^{* * *}$ \\
\hline$(0.000)$ & $(0.000)$ & $(0.000)$ \\
\hline $0.377^{* * *}$ & $0.396^{* * *}$ & $0.407^{* * *}$ \\
\hline$(0.035)$ & $(0.034)$ & $(0.039)$ \\
\hline $0.149^{* * *}$ & $0.128^{* * *}$ & $0.182^{* * *}$ \\
\hline$(0.033)$ & $(0.032)$ & $(0.039)$ \\
\hline 0.027 & 0.014 & $0.059^{*}$ \\
\hline$(0.026)$ & $(0.026)$ & $(0.033)$ \\
\hline$-18.816^{* * *}$ & $-18.367^{* * *}$ & $-18.328^{* * *}$ \\
\hline$(2.219)$ & $(2.206)$ & $(2.243)$ \\
\hline $16.258^{* * *}$ & $15.375^{* * *}$ & $15.401^{* * *}$ \\
\hline$(5.710)$ & $(5.560)$ & $(5.546)$ \\
\hline 0.246 & 0.466 & $0.591^{*}$ \\
\hline \multirow[t]{37}{*}{$(0.331)$} & $(0.324)$ & $(0.329)$ \\
\hline & 0.006 & $0.029^{*}$ \\
\hline & $(0.015)$ & $(0.016)$ \\
\hline & $-0.093^{* * *}$ & $-0.093^{* * *}$ \\
\hline & $(0.005)$ & $(0.005)$ \\
\hline & $0.001^{* * *}$ & $0.001^{* * *}$ \\
\hline & $(0.000)$ & $(0.000)$ \\
\hline & & 0.021 \\
\hline & & $(0.018)$ \\
\hline & & -0.019 \\
\hline & & $(0.026)$ \\
\hline & & -0.006 \\
\hline & & $(0.030)$ \\
\hline & & -0.004 \\
\hline & & $(0.027)$ \\
\hline & & $0.103^{* * *}$ \\
\hline & & $(0.016)$ \\
\hline & & $0.033^{* * *}$ \\
\hline & & $(0.007)$ \\
\hline & & $0.025^{* * *}$ \\
\hline & & $(0.009)$ \\
\hline & & $-0.012^{*}$ \\
\hline & & $(0.007)$ \\
\hline & & $-0.025^{* * *}$ \\
\hline & & $(0.006)$ \\
\hline & & $-0.031^{* * *}$ \\
\hline & & $(0.007)$ \\
\hline & & $-0.075^{*}$ \\
\hline & & $(0.044)$ \\
\hline & & -0.039 \\
\hline & & $(0.043)$ \\
\hline & & 0.027 \\
\hline & & $(0.046)$ \\
\hline & & $-0.113^{* *}$ \\
\hline & & $(0.048)$ \\
\hline & & -0.045 \\
\hline & & $(0.034)$ \\
\hline$-0.138^{* * *}$ & $-0.190^{* * *}$ & $-0.362^{* * *}$ \\
\hline
\end{tabular}




\begin{tabular}{lrrr} 
& $(0.030)$ & $(0.055)$ & $(0.071)$ \\
\hline Adjusted $R^{2}$ & 0.064 & 0.098 & 0.100 \\
Observations & 219,209 & 219,209 & 219,209 \\
\hline Sum VAT-coefficients ${ }^{\phi}$ & 1.150 & 0.944 & 0.904 \\
p-value ${ }^{\phi \phi}$ & 0.586 & 0.834 & 0.826 \\
\hline Standard errors in parentheses & & \\
$* p<0.1, * * p<0.05, * * * p<0.01$ & \\
${ }^{\phi}$ Sum-up of all VAT-related coefficients, i.e. of the first eight coefficients in each column. \\
${ }_{\phi}$ Null hypothesis: Sum of all VAT-related coefficients equals one. \\
\hline \hline
\end{tabular}

\subsection{The VAT}

The introduction of the VAT in the year 1995 and the subsequent increases in 1999, 2001 and 2012 represent exogenous cost shocks to firms. Thus, all these increases at large are an ideal policy experiment to study the (size of) price changes by firms. The results in table 5 indicate that the total effect, i.e., the elasticity of the relative price change with regard to the relative change in the VAT, determined by totaling all the relevant coefficients, is not statistically different from one (or even greater than one) in any of its specifications. ${ }^{20}$ This finding is at a first glance consistent with the hypothesis that firms increase their prices pari passu with the relative change in the VAT, i.e., the tax increase is directly reflected in the prices.

If every sector along the value chain of a product passes the VAT change proportionally into prices, it is optimal for a single firm to raise its price proportionally as well if it wants to keep its markup unchanged. To understand this relationship, let us write the price of a product as the sum of its marginal costs plus the markup. Marginal costs can be expressed as the sum of two components: the costs of input goods or services, denoted $c_{1}$, and the cost of the own added value, e.g., wages, interest rates, etc., denoted $c_{2}$. Thus, the price can be written as

$$
p\left(i_{n}, j, t\right):=\left(\frac{c_{1}\left(i_{n}, j, t\right)}{1+\tau_{t}}+c_{2}\left(i_{n}, j, t\right)\right) \mu\left(i_{n}, j, t\right)\left(1+\tau_{t}\right),
$$

where $\mu\left(i_{n}, j, t\right)$ denotes the markup factor. Assume that the markup factor is independent of $\tau_{t}$. We guess that the input sectors raise their prices proportionally to the VAT increase, hence, $c_{1}$ is proportional to $1+\tau_{t}$. Consequently, the optimal price $p\left(i_{n}, j, t\right)$ is proportional to $1+\tau_{t}$ as well, confirming the initial guess.

However, because our results indicate that average prices rise proportionally with the VAT increase, we can conclude that firms changing their prices, increase them more than one-to-one with the tax increase. As we control for firm-specific state variables, we can conclude that firms (that change their prices) seem to regard a VAT increase as an opportunity to increase their markup.

\footnotetext{
${ }^{20} \mathrm{cp}$. the last two lines in table 5.
} 


\subsection{Endogeneity issues}

In the estimations above, we found that macroeconomic factors have a clear causal effect. However, it is possible that shocks influencing macroeconomic variables, such as real GDP growth, also have an impact on the price setting considerations of firms, i.e., they are occasionally simultaneously determined. ${ }^{21}$ This impact would cause an endogeneity problem, because the error terms in the estimations above are not uncorrelated with the regressors. As a result, our estimated coefficients might be inconsistent.

To address this possible bias, we re-estimate our chosen specifications using an instrumental variable (IV) approach. Recall that our price data series rely on non-tradable services. However, the Swiss economy in general is a typical example of a small open economy. Thus, it is clear that the macroeconomic or policy parameters of the most important trading partners (the European Union and the US) have impacts on macroeconomic conditions in Switzerland. A good example would be the short-term interest rates set by the respective central bank. They have direct impacts on the exchange rate and are therefore also correlated with the Swiss business cycle. Moreover, the shortterm interest rate for the Swiss franc is also heavily influenced by the interest rates of Switzerland's most important trading partners. However, there is no reason to believe that non-trading firms consider foreign central banking policy in their pricing decisions, making the short-term interest rates of the trading partners a valid instrument.

In the re-estimation, each macroeconomic variable is added separately to the standard regression and then is instrumented using the short-term interest rates (and their lags) of the European Union and the US. ${ }^{22}$ This procedure also allows us also to determine whether our results are robust to the individual inclusion of the macroeconomic variables. For the non-linear conditional logit model, our estimation relies on the instrumental variable approach proposed by Terza et al. (2008). Note that standard errors in these estimations are bootstrapped to ensure that they remain consistent and comparable. ${ }^{23}$ The estimation procedure for the linear standard TSLS estimation follows the procedure of Schaffer (2005) to obtain unbiased, clustered standard errors.

Tables A.7 - A.8 in appendix ?? report the results of the IV regressions. As can be observed, the IV regressions generally tend to report stronger effects relative to the standard estimations with regard to the impact of macroeconomic factors (in both the conditional logit and the standard OLS model). This difference also holds for the impact of the interest rate on the relative price change, which is even more strongly negative in the IV regression. Moreover, the impact of the real exchange rate index is clearly positive in the IV regression. At a minimum, this finding provides us with an indication that

\footnotetext{
${ }^{21}$ Note that we do not consider the VAT to be a potentially endogenous variable, because the VAT is not used as an instrument to conduct macroeconomic policy in Switzerland. The setting of the VAT is the result of a political process, and the time of introduction/change is random. See Strittmatter and Sunde (2013) for a similar discussion of health insurance.

${ }^{22}$ Data on the particular short-term interest rates are provided by the ECB and the FED, respectively.

${ }^{23}$ The bootstrapping procedure consists of 1,000 replications.
} 
regarding the impact of the real exchange rate index, in concretizing our results from the standard regressions in table 5, the income effect is likely to dominate in general, i.e., including over a longer time horizon.

\subsection{Additional robustness checks}

In this section, we test whether our results are robust to data preconditions. First, we estimate our regressions by restricting the time frame considered to the period after 1995 . With this restriction we exclude the introduction of the VAT, which can be considered an exceptional incident in the sense that the increase in the VAT was extraordinary high at this point in time (compared to other increases in the VAT), which might lead to overestimation of the effects of the VAT. Moreover, as we observed in the descriptive statistics section, the number of price changes was very high in 1995. The respective results can be found in appendix B.1. Surprisingly, the effects of the VAT increase somewhat when considering the restricted time frame, whereas the impacts of the other variables remain approximately constant.

Second, we modify our data in the sense that we assume the first data point in each price series to be a price change, i.e., $k_{1}\left(i_{n}, j\right) \equiv t_{1} \forall i, j$. This procedure expands the number of available data points, making the estimation more precise; however, Klenow and Kryvtsov (2008) argue that the results may become biased. Nevertheless, our results do not generally reflect a notable difference between the usage of two data types in the estimations. See appendix B.2 for details.

Third, we perform our estimations separately for the four product groups (i.e., cinema tickets, hairdresser services, drinks at restaurants, and food at restaurants). ${ }^{24}$ The results suggest that the impact of a change in the VAT is stronger in the restaurant and hairdresser sectors but is less pronounced for cinemas. Moreover, the impact of the real exchange rate appears indeterminate in the cinema sector, whereas the hairdresser sector is the most affected. However, these results are not surprising, because the cinema sector tends to change prices less frequently than the other sectors.

Overall, the robustness checks confirm our findings from the previous estimations. Time-dependent variables, with exception of the seasonality impact, play a less important role relative to state-dependent factors. This especially holds for the relative standing in the market, measured as the relative deviation from the mean price. Finally, the estimations provide evidence that changes in the VAT are taken as a chance by firms to increase the markup. The following section shows that changes in the VAT can also have an impact on the distributions of prices.

\section{Price dispersion}

A unique feature of our data set is that it allows us to estimate price dispersion (variance and higher moments) for each of the 73 product types at each point in time,

\footnotetext{
${ }^{24}$ The results are available on request.
} 
further allowing us to analyze the factors that might influence the distribution of prices from a more macroeconomic perspective. For this purpose, we rely on the data on the relative deviation from the mean product price of each observed price, i.e., $\rho\left(i_{n}, j, t\right)$.

In particular, we denote

$$
V A R(\rho(i, t)):=\frac{1}{A(i, t)} \sum_{n, j} \rho\left(i_{n}, j, t\right)^{2}
$$

as the variance,

$$
S K E(\rho(i, t)):=\frac{1}{A(i, t)} \sum_{n, j} \rho\left(i_{n}, j, t\right)^{3}
$$

as the skewness, and

$$
K U R(\rho(i, t)):=\frac{1}{A(i, t)} \sum_{n, j} \rho\left(i_{n}, j, t\right)^{4}
$$

as the kurtosis of the relative price of product $i$ in period $t$.

Based on this calculation, we perform in a first specification (denoted as specification 1) a regression of the variance, the skewness and the kurtosis on their own first two lags, and on the change in the VAT. Furthermore, we again include dummies for the second quarter of 2000 and for the number of the quarter in each year. Additionally, we introduce a dummy for all periods after 2000Q2, because we might have a structural break after this point in time. In a second specification, we also add the year-on-year real GDP growth rate (denoted as specification 2). The estimation results are presented in table 6 .

The results show that a rise in the VAT decreases the variance of prices. This may stem therefrom that firms charging relatively low prices vis-à-vis their competitors at the time of the VAT increase, raise their prices more strongly. Hence, they tend to regard this increase as an opportunity to close the gap relative to producers, which already charge high prices. This finding would also, to some extent, explain the puzzling finding from section 4.4, in which we found evidence that increases in the VAT are perceived as an opportunity for relatively high price increases. No significant impact can be observed regarding the business cycle, because the coefficients are jointly not different from zero. ${ }^{25}$

\footnotetext{
${ }^{25}$ The p-value of the respective F-test is 0.134 . Note that the inclusion of other macroeconomic factors would not show any significant results either (i.e., even not for single coefficients).
} 
Table 6: Estimation results for price dispersion.

\begin{tabular}{|c|c|c|c|c|c|c|}
\hline Dep. variable, (specification) & $\operatorname{VAR}(\rho(i, t)),(1)$ & $V A R(\rho(i, t)),(2)$ & $\operatorname{SKE}(\rho(i, t)),(1)$ & $S K E(\rho(i, t)),(2)$ & $K U R(\rho(i, t)),(1)$ & $K U R(\rho(i, t)),(2)$ \\
\hline Lag 1 period & $\begin{array}{c}0.653^{* * *} \\
(0.148)\end{array}$ & $\begin{array}{c}0.653^{* * *} \\
(0.148)\end{array}$ & $\begin{array}{c}0.801^{* * *} \\
(0.0808)\end{array}$ & $\begin{array}{c}0.801^{* * *} \\
(0.080)\end{array}$ & $\begin{array}{c}0.668^{* * *} \\
(0.125)\end{array}$ & $\begin{array}{c}0.668^{* * *} \\
(0.125)\end{array}$ \\
\hline Lag 2 period & $\begin{array}{c}0.212 * \\
(0.120)\end{array}$ & $\begin{array}{c}0.211 * \\
(0.120)\end{array}$ & $\begin{array}{l}0.097 \\
(0.066)\end{array}$ & $\begin{array}{c}0.096 \\
(0.066)\end{array}$ & $\begin{array}{l}0.179^{* *} \\
(0.085)\end{array}$ & $\begin{array}{l}0.179^{* *} \\
(0.085)\end{array}$ \\
\hline Rel. change VAT & $\begin{array}{c}-4.170^{* *} \\
(1.738)\end{array}$ & $\begin{array}{l}-6.501^{* * *} \\
(2.067)\end{array}$ & $\begin{array}{c}-0.004 \\
(0.004)\end{array}$ & $\begin{array}{c}-0.006 \\
(0.005)\end{array}$ & $\begin{array}{c}-0.007 \\
(0.031)\end{array}$ & $\begin{array}{c}-0.022 \\
(0.039)\end{array}$ \\
\hline Dummy 1. quarter & $\begin{array}{c}5.824 \\
(9.190)\end{array}$ & $\begin{array}{c}6.876 \\
(9.139)\end{array}$ & $\begin{array}{c}-0.005 \\
(0.015)\end{array}$ & $\begin{array}{c}-0.004 \\
(0.015)\end{array}$ & $\begin{array}{c}-0.039 \\
(0.092)\end{array}$ & $\begin{array}{c}-0.029 \\
(0.094)\end{array}$ \\
\hline Dummy 2. quarter & $\begin{array}{l}-2.849 \\
(10.485)\end{array}$ & $\begin{array}{l}-2.807 \\
(10.714)\end{array}$ & $\begin{array}{c}0.001 \\
(0.011)\end{array}$ & $\begin{array}{c}0.001 \\
(0.011)\end{array}$ & $\begin{array}{c}0.049 \\
(0.065)\end{array}$ & $\begin{array}{c}0.052 \\
(0.065)\end{array}$ \\
\hline Dummy 3. quarter & $\begin{array}{c}-9.259 \\
(8.093)\end{array}$ & $\begin{array}{c}-8.873 \\
(8.249)\end{array}$ & $\begin{array}{c}0.018 \\
(0.014)\end{array}$ & $\begin{array}{l}0.018 \\
(0.014)\end{array}$ & $\begin{array}{c}0.170^{*} \\
(0.097)\end{array}$ & $\begin{array}{c}0.175^{*} \\
(0.098)\end{array}$ \\
\hline Dummy 2000Q2 & $\begin{array}{l}274.377^{* *} \\
(133.988)\end{array}$ & $\begin{array}{l}269.980^{* *} \\
(134.362)\end{array}$ & $\begin{array}{l}0.428^{* *} \\
(0.167)\end{array}$ & $\begin{array}{l}0.412^{* *} \\
(0.170)\end{array}$ & $\begin{array}{c}2.518 \\
(1.580)\end{array}$ & $\begin{array}{c}2.447 \\
(1.593)\end{array}$ \\
\hline Post 2000Q2 & $\begin{array}{l}13.412^{*} \\
(7.621)\end{array}$ & $\begin{array}{l}12.140 \\
(7.312)\end{array}$ & $\begin{array}{c}0.014 \\
(0.017)\end{array}$ & $\begin{array}{c}0.013 \\
(0.017)\end{array}$ & $\begin{array}{c}0.002 \\
(0.130)\end{array}$ & $\begin{array}{c}0.015 \\
(0.126)\end{array}$ \\
\hline GDP growth, yoy & & $\begin{array}{l}-1.934 \\
(3.560)\end{array}$ & & $\begin{array}{c}0.001 \\
(0.007)\end{array}$ & & $\begin{array}{l}-0.010 \\
(0.040)\end{array}$ \\
\hline Lag 1 quarter & & $\begin{array}{c}4.339 \\
(3.740)\end{array}$ & & $\begin{array}{l}-0.004 \\
(0.008)\end{array}$ & & $\begin{array}{c}-0.003 \\
(0.045)\end{array}$ \\
\hline Lag 2 quarters & & $\begin{array}{c}1.023 \\
(3.439)\end{array}$ & & $\begin{array}{c}0.011 \\
(0.010)\end{array}$ & & $\begin{array}{c}0.050 \\
(0.058)\end{array}$ \\
\hline Lag 3 quarters & & $\begin{array}{r}-7.629^{*} \\
(4.073)\end{array}$ & & $\begin{array}{c}-0.012 \\
(0.010)\end{array}$ & & $\begin{array}{c}-0.095 \\
(0.069)\end{array}$ \\
\hline Lag 4 quarters & & $\begin{array}{l}5.839^{* *} \\
(2.440)\end{array}$ & & $\begin{array}{c}0.005 \\
(0.005)\end{array}$ & & $\begin{array}{c}0.034 \\
(0.034)\end{array}$ \\
\hline Constant & $\begin{array}{l}116.386^{*} \\
(67.769)\end{array}$ & $\begin{array}{l}114.459 \\
(70.621)\end{array}$ & $\begin{array}{l}0.067^{* *} \\
(0.029)\end{array}$ & $\begin{array}{r}0.065^{*} \\
(0.033)\end{array}$ & $\begin{array}{l}0.804^{* *} \\
(0.352)\end{array}$ & $\begin{array}{l}0.830^{* *} \\
(0.377)\end{array}$ \\
\hline Adjusted $R^{2}$ & 0.689 & 0.689 & 0.791 & 0.791 & 0.677 & 0.677 \\
\hline
\end{tabular}




\section{Conclusion}

Using a data set of the price series underlying the Swiss CPI, we analyzed the factors that influence the price setting behavior of firms and the price dispersion within a small open economy. Contrary to most previous research, our data set not only allowed us to investigate the factors that influence the frequency (i.e., the extensive margin) but also the (average) size of price changes (i.e., the intensive margin). Moreover, the development of individual prices can be observed over a relatively long period of time. We found that the time span between price changes is not particularly important in determining the sizes of price changes, supporting the finding reported in previous papers that timedependent variables are of little importance. This finding does not apply to seasonality, because in agreement with numerous previous studies, we found that the frequency and size of price changes are highly seasonal, because firms generally tend to adjust prices at the beginning of the calendar year.

A unique strength of our dataset is that we can look at relevant state-dependent variables, and indeed they play an important role. Accumulated inflation between price changes has a clear impact; however, we observe an underproportional influence. More important is the relative standing in the market, measured as the relative deviation from the mean price of a specific product in the sample. Even more, this variable, which is constructed from the data, significantly improves the goodness of the fit of our estimations, although the absolut impact is rather small in size.

Furthermore, our results indicate that the influence of macroeconomic determinants on price setting behavior is rather small in size and in explanatory power. Nevertheless, we found some positive impacts of real GDP growth and the real exchange rate index at the extensive margin. The latter can be explained by our data set only consisting of the prices of non-tradable services. As imports become less expensive in response to a stronger home currency, the demand for this type of services can increase due to a dominating income effect. At a minimum, our IV regressions also support this hypothesis at the intensive margin. This result is of particular interest for models considering the impact of exchange rate movements on the general price level as there seem to be more effects at work than the simple pass-through. Moreover, we also found that a positive change in the short-term interest rate has a negative impact on both the probability and the size of a price change.

We placed an especial emphasis on the role of the VAT as an important policy parameter. Our results indicate that increases in the VAT raise the average price level proportionally implying that firms, that indeed adjust prices, do this over-proportionally. An increase in the VAT, which can be regarded as an external policy shock, may be interpreted as an opportunity for firms to increase their margins. This insight can notably help improving forecasts of price developments when it comes to changes in the VAT.

Finally, the data set also allowed us to estimate the price dispersion for each product category. By performing a regression of several moments on their lags, changes in the 
VAT, and the business cycle, we found some indication that an increase in the VAT reduces the variance of prices within an economy. It might be a nearby explanation that firms charging a relative low price take the VAT increase as a chance to narrow the gap to their competitors, however, a theoretical substantiation of the role of the VAT that elucidates our findings is left for future research. 


\section{References}

Altissimo, F., Mojon, B., Zaffaroni, P., 2009. Can aggregation explain the persistence of inflation? Journal of Monetary Economics 56 (2), 231 - 241.

Álvarez, L. J., Dhyne, E., Hoeberichts, M., Kwapil, C., Bihan, H. L., Lünnemann, P., Martins, F., Sabbatini, R., Stahl, H., Vermeulen, P., Vilmunen, J., 2006. Sticky prices in the euro area: A summary of new micro-evidence. Journal of the European Economic Association 4 (2-3), 575-584.

Bils, M., Klenow, P. J., 2004. Some evidence on the importance of sticky prices. Journal of Political Economy 112 (5), 947-985.

Boivin, J., Giannoni, M. P., Mihov, I., 2009. Sticky prices and monetary policy: Evidence from disaggregated us data. American Economic Review 99 (1), 350-384.

Borenstein, S., Rose, N. L., 1994. Competition and price dispersion in the u.s. airline industry. Journal of Political Economy 102 (4), 653-683.

Calvo, G. A., 1983. Staggered prices in a utility-maximizing framework. Journal of Monetary Economics $12(3), 383-398$.

Cecchetti, S. G., 1986. The frequency of price adjustment : A study of the newsstand prices of magazines. Journal of Econometrics 31 (3), 255-274.

Clay, K., Krishnan, R., Wolff, E., 2001. Prices and price dispersion on the web: Evidence from the online book industry. The Journal of Industrial Economics 49 (4), 521-539.

Dotsey, M., King, R. G., Wolman, A. L., 1999. State-dependent pricing and the general equilibrium dynamics of money and output. Quarterly Journal of Economics 114 (2), 655-690.

Fehr, E., Goette, L., 2005. Robustness and real consequence of nominal wage rigidity. Journal of Monetary Economics 52 (4), 779-804.

Gertler, M., Leahy, J., 2008. A phillips curve with an ss foundation. Journal of Political Economy 116 (3), $533-572$.

Golosov, M., Lucas, R. E., April 2007. Menu costa and philips curves. Journal of Political Economy $115(2), 171-199$

Hoeberichts, M., Stokman, A., 2011. Price dispersion in europe: Does the business cycle matter? DNB Working Papers 285, Netherlands Central Bank, Research Department.

Honoré, B. E., Kaufmann, D., Lein, S., 2012. Asymmetries in price-setting behavior: New microeconometric evidence from switzerland. Journal of Money, Credit and Banking 44 (s2), 211-236.

Kaplan, G., Menzio, G., 2014. The morphology of price dispersion. Working Paper 19877, National Bureau of Economic Research.

Kashyap, A. K., 1995. Sticky prices: New evidence from retail catalogs. Quarterly Journal of Economics 110 (1), 245-274.

Kaufmann, D., 2009. Price-setting behaviour in switzerland: Evidence from cpi micro data. Swiss Journal of Economics and Statistics (SJES) 145 (III), 293-349.

Kaufmann, D., Lein, S. M., 2013. Sticky prices or rational inattention - what can we learn from sectoral price data? European Economic Review 64 (0), $384-394$.

Klenow, P. J., Kryvtsov, O., 2008. State-dependent or time-dependent pricing: Does it matter for recent u.s. inflation?. Quarterly Journal of Economics 123 (3), 863-904.

Lach, S., Tsiddon, D., 1992. The Behavior of Prices and Inflation: An Empirical Analysis of Disaggregated Price Data. Journal of Political Economy 100 (2), 349-89.

Lein, S. M., 2010. When do firms adjust prices? evidence from micro panel data. Journal of Monetary Economics 57 (6), 696-715.

Maćkowiak, B., Moench, E., Wiederholt, M., 2009. Sectoral price data and models of price setting. Journal of Monetary Economics 56, Supplement (0), S78 - S99, supplement issue: December 12-13, 2008 Research Conference on 'Monetary Policy under Imperfect Information' Sponsored by the Swiss National Bank (http://www.snb.ch) and Study Center Gerzensee (www.szgerzensee.ch).

Maćkowiak, B., Wiederholt, M., 2009. Optimal sticky prices under rational inattention. American Economic Review 99 (3), 769-803. 
Mankiw, N. G., Reis, R., 2002. Sticky information versus sticky prices: A proposal to replace the new keynesian phillips curve. The Quarterly Journal of Economics 117 (4), 1295-1328.

Nakamura, E., Steinsson, J., 2008. Five facts about prices: a reevaluation of menu cost models. Quarterly Journal of Economics 123 (4), 1415-1464.

Rotemberg, J. J., 1982. Monopolistic price adjustment and aggregate output. Review of Economic Studies 49 (4), 517-531.

Schaffer, M. E., 2005. Xtivreg2: Stata module to perform extended iv/2sls, gmm and ac/hac, liml and kclass regression for panel data models. Statistical Software Components, Boston College Department of Economics.

Sengupta, A., Wiggins, S. N., 2014. Airline pricing, price dispersion, and ticket characteristics on and off the internet. American Economic Journal: Economic Policy 6 (1), 272-307.

Sorensen, A. T., 2000. Equilibrium price dispersion in retail markets for prescription drugs. Journal of Political Economy 108 (4), 833-850.

Strittmatter, A., Sunde, U., 2013. Health and economic development-evidence from the introduction of public health care. Journal of Population Economics 26 (4), 1549-1584.

Taylor, J. B., 1979. Staggered wage setting in a macro model. American Economic Review 69 (2), $108-13$.

Taylor, J. B., 1980. Aggregate dynamics and staggered contracts. Journal of Political Economy 88 (1) $1-23$.

Terza, J. V., Basu, A., Rathouz, P. J., 2008. Two-stage residual inclusion estimation: Addressing endogeneity in health econometric modeling. Journal of Health Economics 27 (3), 531-543. 
Appendix 


\section{A. IV regressions}

The following tables present the results for the IV-estimations. Model 1 includes real GDP growth, model 2 the relative change of the real exchange rate index, and model 3 the short-term interest rate (i.e., the first difference of the Swiss LIBOR). For each model, the three month LIBOR of the Euro Zone and of the US are used as instruments.

Table A.7: Estimation results for IV regressions: Size of relative price changes.

\begin{tabular}{|c|c|c|c|c|c|c|}
\hline Rel. price change & model1 & model1IV & model2 & model2IV & model3 & model3IV \\
\hline Rel. change VAT & $\begin{array}{l}0.988^{* * *} \\
(0.047)\end{array}$ & $\begin{array}{l}1.002^{* * *} \\
(0.048)\end{array}$ & $\begin{array}{l}0.985^{* * *} \\
(0.048)\end{array}$ & $\begin{array}{l}0.982^{* * *} \\
(0.054)\end{array}$ & $\begin{array}{l}1.002^{* * *} \\
(0.047)\end{array}$ & $\begin{array}{l}1.027^{* * *} \\
(0.048)\end{array}$ \\
\hline Rel.chan. VAT, 1 Lag(s) & $\begin{array}{l}0.031^{* *} \\
(0.013)\end{array}$ & $\begin{array}{c}-0.028 \\
(0.021)\end{array}$ & $\begin{array}{c}0.002 \\
(0.013)\end{array}$ & $\begin{array}{c}-0.104^{* * *} \\
(0.022)\end{array}$ & $\begin{array}{c}0.017 \\
(0.012)\end{array}$ & $\begin{array}{c}0.003 \\
(0.015)\end{array}$ \\
\hline Rel.chan. VAT, 2 Lag(s) & $\begin{array}{l}0.029^{* * *} \\
(0.010)\end{array}$ & $\begin{array}{c}0.028 \\
(0.019)\end{array}$ & $\begin{array}{c}0.015 \\
(0.010)\end{array}$ & $\begin{array}{c}-0.083^{* * *} \\
(0.026)\end{array}$ & $\begin{array}{c}-0.000 \\
(0.010)\end{array}$ & $\begin{array}{c}-0.050^{* * *} \\
(0.014)\end{array}$ \\
\hline Fut.VAT-incr. known, 1 Lag(s) & $\begin{array}{l}0.097^{* * *} \\
(0.032)\end{array}$ & $\begin{array}{l}0.105^{* * *} \\
(0.034)\end{array}$ & $\begin{array}{l}0.083^{* * *} \\
(0.030)\end{array}$ & $\begin{array}{c}-0.037 \\
(0.033)\end{array}$ & $\begin{array}{l}0.095^{* * *} \\
(0.031)\end{array}$ & $\begin{array}{l}0.099^{* * *} \\
(0.031)\end{array}$ \\
\hline Fut.VAT-incr. known, 2 Lag(s) & $\begin{array}{l}0.058^{* * *} \\
(0.016)\end{array}$ & $\begin{array}{c}0.009 \\
(0.021)\end{array}$ & $\begin{array}{l}0.055^{* * *} \\
(0.016)\end{array}$ & $\begin{array}{c}0.039 \\
(0.032)\end{array}$ & $\begin{array}{l}0.065^{* * *} \\
(0.015)\end{array}$ & $\begin{array}{l}0.091^{* * *} \\
(0.015)\end{array}$ \\
\hline Fut.VAT-incr. known, 3 Lag(s) & $\begin{array}{l}0.040^{* *} \\
(0.018)\end{array}$ & $\begin{array}{l}0.050^{* *} \\
(0.021)\end{array}$ & $\begin{array}{c}0.012 \\
(0.018)\end{array}$ & $\begin{array}{l}-0.115^{* * *} \\
(0.030)\end{array}$ & $\begin{array}{r}0.029^{*} \\
(0.017)\end{array}$ & $\begin{array}{c}0.035^{* *} \\
(0.018)\end{array}$ \\
\hline Fut.VAT-incr. known, 4 Lag(s) & $\begin{array}{c}0.039 \\
(0.028)\end{array}$ & $\begin{array}{l}0.093^{* * *} \\
(0.030)\end{array}$ & $\begin{array}{c}-0.014 \\
(0.029)\end{array}$ & $\begin{array}{c}-0.046 \\
(0.031)\end{array}$ & $\begin{array}{c}0.036 \\
(0.027)\end{array}$ & $\begin{array}{c}0.050^{*} \\
(0.029)\end{array}$ \\
\hline Fut.VAT-incr. known, 5 Lag(s) & $\begin{array}{c}0.214 \\
(0.261)\end{array}$ & $\begin{array}{l}0.988^{* * *} \\
(0.367)\end{array}$ & $\begin{array}{c}-0.114 \\
(0.236)\end{array}$ & $\begin{array}{c}-0.306 \\
(0.259)\end{array}$ & $\begin{array}{c}0.300 \\
(0.321)\end{array}$ & $\begin{array}{c}0.095 \\
(0.526)\end{array}$ \\
\hline Acc.sec.infl., $\pi\left(i_{n}, j, t\right)$ & $\begin{array}{c}0.018 \\
(0.015)\end{array}$ & $\begin{array}{c}0.002 \\
(0.017)\end{array}$ & $\begin{array}{c}0.015 \\
(0.015)\end{array}$ & $\begin{array}{c}-0.040^{*} \\
(0.022)\end{array}$ & $\begin{array}{c}0.014 \\
(0.015)\end{array}$ & $\begin{array}{c}-0.014 \\
(0.016)\end{array}$ \\
\hline Periods since last price change, $z\left(i_{n}, j, t,\right)$ & $\begin{array}{l}0.020^{* * *} \\
(0.005)\end{array}$ & $\begin{array}{l}0.030^{* * *} \\
(0.006)\end{array}$ & $\begin{array}{l}0.020^{* * *} \\
(0.005)\end{array}$ & $\begin{array}{l}0.048^{* * *} \\
(0.009)\end{array}$ & $\begin{array}{l}0.021^{* * *} \\
(0.005)\end{array}$ & $\begin{array}{l}0.037^{* * *} \\
(0.006)\end{array}$ \\
\hline$z\left(i_{n}, j, t,\right)^{2}$ & $\begin{array}{c}-0.001^{* * *} \\
(0.000)\end{array}$ & $\begin{array}{c}-0.001^{* * *} \\
(0.000)\end{array}$ & $\begin{array}{c}-0.001^{* * *} \\
(0.000)\end{array}$ & $\begin{array}{c}-0.001^{* * *} \\
(0.000)\end{array}$ & $\begin{array}{c}-0.001^{* * *} \\
(0.000)\end{array}$ & $\begin{array}{c}-0.001^{* * *} \\
(0.000)\end{array}$ \\
\hline Dummy 1st quarter & $\begin{array}{l}0.413^{* * *} \\
(0.036)\end{array}$ & $\begin{array}{l}0.426^{* * *} \\
(0.036)\end{array}$ & $\begin{array}{l}0.404^{* * *} \\
(0.037)\end{array}$ & $\begin{array}{l}0.241^{* * *} \\
(0.078)\end{array}$ & $\begin{array}{l}0.364^{* * *} \\
(0.033)\end{array}$ & $\begin{array}{l}0.276^{* * *} \\
(0.036)\end{array}$ \\
\hline Dummy 2nd quarter & $\begin{array}{l}0.125^{* * *} \\
(0.034)\end{array}$ & $\begin{array}{l}0.165^{* * *} \\
(0.039)\end{array}$ & $\begin{array}{l}0.167^{* * *} \\
(0.034)\end{array}$ & $\begin{array}{l}0.220^{* * *} \\
(0.042)\end{array}$ & $\begin{array}{l}0.094^{* * *} \\
(0.034)\end{array}$ & $\begin{array}{c}0.060 \\
(0.041)\end{array}$ \\
\hline Dummy 3rd quarter & $\begin{array}{c}0.022 \\
(0.026)\end{array}$ & $\begin{array}{l}0.064^{* *} \\
(0.028)\end{array}$ & $\begin{array}{c}0.038 \\
(0.028)\end{array}$ & $\begin{array}{c}-0.008 \\
(0.062)\end{array}$ & $\begin{array}{c}0.017 \\
(0.029)\end{array}$ & $\begin{array}{c}0.059 \\
(0.040)\end{array}$ \\
\hline Price relative to mean price, $\rho\left(i_{n}, j, t-1\right)$ & $\begin{array}{l}-0.093^{* * *} \\
(0.005)\end{array}$ & $\begin{array}{l}-0.092^{* * *} \\
(0.005)\end{array}$ & $\begin{array}{l}-0.093^{* * *} \\
(0.005)\end{array}$ & $\begin{array}{l}-0.090^{* * *} \\
(0.005)\end{array}$ & $\begin{array}{l}-0.093^{* * *} \\
(0.005)\end{array}$ & $\begin{array}{l}-0.092^{* * *} \\
(0.005)\end{array}$ \\
\hline$\rho\left(i_{n}, j, t-1\right)^{2}$ & $\begin{array}{l}0.001^{* * *} \\
(0.000)\end{array}$ & $\begin{array}{l}0.001^{* * *} \\
(0.000)\end{array}$ & $\begin{array}{l}0.001^{* * *} \\
(0.000)\end{array}$ & $\begin{array}{l}0.001^{* * *} \\
(0.000)\end{array}$ & $\begin{array}{l}0.001^{* * *} \\
(0.000)\end{array}$ & $\begin{array}{l}0.001^{* * *} \\
(0.000)\end{array}$ \\
\hline
\end{tabular}




\begin{tabular}{|c|c|c|c|c|c|c|c|}
\hline & GDP growth, yoy & 0.004 & -0.014 & & & & \\
\hline & Lag 1 quarters & $\begin{array}{l}(0.014) \\
-0.021\end{array}$ & $-0.217^{* * *}$ & & & & \\
\hline & & $(0.024)$ & $(0.062)$ & & & & \\
\hline & Lag 2 quarters & 0.041 & $0.205^{* * *}$ & & & & \\
\hline & & $(0.027)$ & $(0.068)$ & & & & \\
\hline & Lag 3 quarters & $\begin{array}{c}-0.023 \\
(0.022)\end{array}$ & $\begin{array}{c}0.024 \\
(0.068)\end{array}$ & & & & \\
\hline & Lag 4 quarters & $0.067^{* * *}$ & $\begin{array}{l}0.000) \\
0.024\end{array}$ & & & & \\
\hline & & $(0.012)$ & $(0.032)$ & & & & \\
\hline & Sales & $\begin{array}{l}-18.316^{* * *} \\
(2.221)\end{array}$ & $\begin{array}{l}-18.353^{* * *} \\
(2.250)\end{array}$ & $\begin{array}{l}-18.369^{* * *} \\
(2.221)\end{array}$ & $\begin{array}{l}-18.405^{* * *} \\
(2.205)\end{array}$ & $\begin{array}{l}-18.374^{* * *} \\
(2.223)\end{array}$ & $\begin{array}{l}-18.462^{* * *} \\
\quad(2.240)\end{array}$ \\
\hline & Sales end & $\begin{array}{l}15.433^{* * *} \\
(5.551)\end{array}$ & $\begin{array}{l}15.532^{* * *} \\
(5.574)\end{array}$ & $\begin{array}{l}15.349^{* * *} \\
(5.560)\end{array}$ & $\begin{array}{l}15.444^{* * *} \\
(5.499)\end{array}$ & $\begin{array}{l}15.411^{* * *} \\
(5.572)\end{array}$ & $\begin{array}{l}15.443^{* * *} \\
(5.585)\end{array}$ \\
\hline & Dummy 2000Q2 & $\begin{array}{c}0.531 \\
(0.327)\end{array}$ & $\begin{array}{c}0.637^{*} \\
(0.327)\end{array}$ & $\begin{array}{c}0.432 \\
(0.319)\end{array}$ & $\begin{array}{l}0.770^{* *} \\
(0.320)\end{array}$ & $\begin{array}{c}0.515 \\
(0.325)\end{array}$ & $\begin{array}{l}0.822^{* *} \\
(0.344)\end{array}$ \\
\hline & RER index, gr. qoq & & & $\begin{array}{l}0.024^{* * *} \\
(0.006)\end{array}$ & $\begin{array}{c}0.014 \\
(0.029)\end{array}$ & & \\
\hline & Lag 1 quarters & & & $0.027^{* * *}$ & $0.185^{* * *}$ & & \\
\hline ن & Lag 2 quarters & & & $\begin{array}{l}(0.007) \\
-0.002\end{array}$ & $\begin{array}{c}(0.030) \\
0.009\end{array}$ & & \\
\hline & & & & $(0.005)$ & $(0.027)$ & & \\
\hline & Lag 3 quarters & & & $-0.014^{* *}$ & $0.072^{* * *}$ & & \\
\hline & & & & $(0.006)$ & $(0.019)$ & & \\
\hline & Lag 4 quarters & & & $-0.016^{* *}$ & 0.011 & & \\
\hline & $3 \mathrm{~m}$ JBOB 1 st diff & & & $(0.006)$ & $(0.023)$ & $-0073^{* *}$ & \\
\hline & 3m LIBOR, 1st diff. & & & & & $(0.031)$ & $\begin{array}{c}-0.392 \\
(0.061)\end{array}$ \\
\hline & Lag 1 quarters & & & & & $\begin{array}{c}-0.069^{* *} \\
(0.032)\end{array}$ & $\begin{array}{l}-0.350^{* * *} \\
(0.078)\end{array}$ \\
\hline & Lag 2 quarters & & & & & $0.065^{* *}$ & $0.098^{*}$ \\
\hline & & & & & & $(0.032)$ & $(0.057)$ \\
\hline & Lag 3 quarters & & & & & $0.108^{* * *}$ & $\begin{array}{l}0.083 \\
(0.074)\end{array}$ \\
\hline & Lag 4 quarters & & & & & $\begin{array}{l}0.127^{* * *} \\
(0.025)\end{array}$ & $\begin{array}{l}0.230^{* * *} \\
(0.044)\end{array}$ \\
\hline & Adjusted $R^{2}$ & 0.099 & 0.050 & 0.098 & 0.039 & 0.098 & 0.050 \\
\hline & Observations & 219,209 & 219,012 & 219,209 & 219,012 & 219,209 & 219,012 \\
\hline & $\begin{array}{l}\text { Standard errors in parentheses } \\
{ }^{*} p<0.1,{ }^{* *} p<0.05,{ }^{* * *} p<0.01\end{array}$ & & & & & & \\
\hline
\end{tabular}


Table A.8: Cond. logit probability model: IV regressions

\begin{tabular}{|c|c|c|c|c|c|c|}
\hline Panel A: Positive price changes & model1 & model1IV & model2 & model2IV & model3 & model3IV \\
\hline Rel. change VAT & $\begin{array}{c}0.709^{* * *} \\
(0.051)\end{array}$ & $\begin{array}{l}0.603^{* * *} \\
(0.062)\end{array}$ & $\begin{array}{c}0.662^{* * *} \\
(0.051)\end{array}$ & $\begin{array}{l}0.679^{* * *} \\
(0.053)\end{array}$ & $\begin{array}{l}0.735^{* * *} \\
(0.052)\end{array}$ & $\begin{array}{l}0.650^{* * *} \\
(0.052)\end{array}$ \\
\hline Rel.chan. VAT, 1 Lag(s) & $\begin{array}{c}-0.010 \\
(0.055)\end{array}$ & $\begin{array}{c}-0.100 \\
(0.067)\end{array}$ & $\begin{array}{c}-0.077 \\
(0.052)\end{array}$ & $\begin{array}{c}-0.192^{* * *} \\
(0.069)\end{array}$ & $\begin{array}{c}-0.030 \\
(0.052)\end{array}$ & $\begin{array}{c}0.092^{*} \\
(0.051)\end{array}$ \\
\hline Rel.chan. VAT, 2 Lag(s) & $\begin{array}{c}0.004 \\
(0.062)\end{array}$ & $\begin{array}{c}0.113 \\
(0.083)\end{array}$ & $\begin{array}{c}-0.069 \\
(0.060)\end{array}$ & $\begin{array}{c}-0.209^{* * * *} \\
(0.069)\end{array}$ & $\begin{array}{c}-0.082 \\
(0.059)\end{array}$ & $\begin{array}{c}-0.228^{* * *} \\
(0.065)\end{array}$ \\
\hline Fut.VAT-incr. known, 1 Lag(s) & $\begin{array}{l}0.272^{* * * *} \\
(0.054)\end{array}$ & $\begin{array}{l}0.428^{* * *} \\
(0.067)\end{array}$ & $\begin{array}{l}0.220^{* * *} \\
(0.053)\end{array}$ & $\begin{array}{c}0.021 \\
(0.068)\end{array}$ & $\begin{array}{l}0.269^{* * *} \\
(0.053)\end{array}$ & $\begin{array}{l}0.268^{* * *} \\
(0.069)\end{array}$ \\
\hline Fut.VAT-incr. known, 2 Lag(s) & $\begin{array}{l}0.184^{* * *} \\
(0.059)\end{array}$ & $\begin{array}{c}0.060 \\
(0.065)\end{array}$ & $\begin{array}{l}0.156^{* *} \\
(0.061)\end{array}$ & $\begin{array}{l}0.226^{* * *} \\
(0.080)\end{array}$ & $\begin{array}{l}0.231^{* * *} \\
(0.059)\end{array}$ & $\begin{array}{c}0.116 \\
(0.073)\end{array}$ \\
\hline Fut.VAT-incr. known, 3 Lag(s) & $\begin{array}{c}0.029 \\
(0.081)\end{array}$ & $\begin{array}{c}0.120^{*} \\
(0.070)\end{array}$ & $\begin{array}{c}-0.062 \\
(0.088)\end{array}$ & $\begin{array}{c}-0.145 \\
(0.095)\end{array}$ & $\begin{array}{c}0.021 \\
(0.085)\end{array}$ & $\begin{array}{c}0.020 \\
(0.084)\end{array}$ \\
\hline Fut.VAT-incr. known, 4 Lag(s) & $\begin{array}{c}0.098^{*} \\
(0.058)\end{array}$ & $\begin{array}{l}0.199^{* * *} \\
(0.071)\end{array}$ & $\begin{array}{c}-0.075 \\
(0.072)\end{array}$ & $\begin{array}{c}0.074 \\
(0.068)\end{array}$ & $\begin{array}{c}0.113^{*} \\
(0.058)\end{array}$ & $\begin{array}{l}0.295^{* * *} \\
(0.074)\end{array}$ \\
\hline Fut.VAT-incr. known, 5 Lag(s) & $\begin{array}{l}1.750^{* *} \\
(0.692)\end{array}$ & $\begin{array}{l}5.964^{* * *} \\
(1.386)\end{array}$ & $\begin{array}{c}0.431 \\
(0.615)\end{array}$ & $\begin{array}{l}1.163^{*} \\
(0.706)\end{array}$ & $\begin{array}{l}2.111^{* *} \\
(0.848)\end{array}$ & $\begin{array}{c}1.831 \\
(1.491)\end{array}$ \\
\hline Periods since last price change, $z\left(i_{n}, j, t,\right)$ & $\begin{array}{l}0.080^{* * *} \\
(0.014)\end{array}$ & $\begin{array}{l}0.092^{* * *} \\
(0.016)\end{array}$ & $\begin{array}{l}0.087^{* * *} \\
(0.014)\end{array}$ & $\begin{array}{l}0.115^{* * *} \\
(0.019)\end{array}$ & $\begin{array}{l}0.081^{* * *} \\
(0.014)\end{array}$ & $\begin{array}{l}0.130^{* * *} \\
(0.018)\end{array}$ \\
\hline$z\left(i_{n}, j, t,\right)^{2}$ & $\begin{array}{l}-0.002^{* * *} \\
(0.000)\end{array}$ & $\begin{array}{c}-0.002^{* * *} \\
(0.000)\end{array}$ & $\begin{array}{c}-0.002^{* * *} \\
(0.000)\end{array}$ & $\begin{array}{c}-0.002^{* * *} \\
(0.000)\end{array}$ & $\begin{array}{c}-0.002^{* * *} \\
(0.000)\end{array}$ & $\begin{array}{c}-0.002^{* * *} \\
(0.000)\end{array}$ \\
\hline Dummy 1st quarter & $\begin{array}{l}1.371^{* * *} \\
(0.097)\end{array}$ & $\begin{array}{l}1.616^{* * *} \\
(0.118)\end{array}$ & $\begin{array}{l}1.357^{* * *} \\
(0.101)\end{array}$ & $\begin{array}{l}1.078^{* * *} \\
(0.117)\end{array}$ & $\begin{array}{l}1.234^{* * *} \\
(0.090)\end{array}$ & $\begin{array}{l}1.344^{* * *} \\
(0.133)\end{array}$ \\
\hline Dummy 2nd quarter & $\begin{array}{l}0.584^{* * *} \\
(0.104)\end{array}$ & $\begin{array}{l}0.870^{* * *} \\
(0.134)\end{array}$ & $\begin{array}{l}0.672^{* * *} \\
(0.104)\end{array}$ & $\begin{array}{l}0.729^{* * *} \\
(0.114)\end{array}$ & $\begin{array}{l}0.490^{* * *} \\
(0.107)\end{array}$ & $\begin{array}{c}0.131 \\
(0.122)\end{array}$ \\
\hline Dummy 3rd quarter & $\begin{array}{c}0.139 \\
(0.087)\end{array}$ & $\begin{array}{l}0.557^{* * *} \\
(0.110)\end{array}$ & $\begin{array}{l}0.209^{* *} \\
(0.089)\end{array}$ & $\begin{array}{c}0.117 \\
(0.109)\end{array}$ & $\begin{array}{c}0.141 \\
(0.087)\end{array}$ & $\begin{array}{c}0.113 \\
(0.112)\end{array}$ \\
\hline Sales & $\begin{array}{c}-13.709^{* * *} \\
(0.451)\end{array}$ & $\begin{array}{c}-14.105^{* * *} \\
(0.984)\end{array}$ & $\begin{array}{c}-13.829^{* * *} \\
(0.520)\end{array}$ & $\begin{array}{c}-14.442^{* * *} \\
(0.904)\end{array}$ & $\begin{array}{c}-13.826^{* * *} \\
(0.471)\end{array}$ & $\begin{array}{c}-14.466^{* * *} \\
(0.861)\end{array}$ \\
\hline Sales end & $\begin{array}{l}2.941^{* * *} \\
(0.497)\end{array}$ & $\begin{array}{l}3.124^{* * *} \\
(0.913)\end{array}$ & $\begin{array}{l}2.703^{* * *} \\
(0.478)\end{array}$ & $\begin{array}{l}3.133^{* * *} \\
(0.566)\end{array}$ & $\begin{array}{l}2.864^{* * *} \\
(0.499)\end{array}$ & $\begin{array}{l}3.274^{* * *} \\
(0.563)\end{array}$ \\
\hline Dummy 2000Q2 & $\begin{array}{l}1.205^{* * *} \\
(0.182)\end{array}$ & $\begin{array}{l}1.241^{* * *} \\
(0.302)\end{array}$ & $\begin{array}{l}1.123^{* * *} \\
(0.163)\end{array}$ & $\begin{array}{l}2.213^{* * *} \\
(0.217)\end{array}$ & $\begin{array}{l}1.066^{* * *} \\
(0.169)\end{array}$ & $\begin{array}{l}2.162^{* * *} \\
(0.303)\end{array}$ \\
\hline Acc.sec.infl., $\pi\left(i_{n}, j, t\right)$ & $\begin{array}{l}0.140^{* * *} \\
(0.035)\end{array}$ & $\begin{array}{l}0.139^{* * *} \\
(0.034)\end{array}$ & $\begin{array}{l}0.103^{* * *} \\
(0.036)\end{array}$ & $\begin{array}{c}0.081 \\
(0.051)\end{array}$ & $\begin{array}{l}0.135^{* * *} \\
(0.035)\end{array}$ & $\begin{array}{c}0.031 \\
(0.037)\end{array}$ \\
\hline Price relative to mean price, $\rho\left(i_{n}, j, t-1\right)$ & $\begin{array}{l}-0.072^{* * *} \\
(0.005)\end{array}$ & $\begin{array}{l}-0.072^{* * *} \\
(0.004)\end{array}$ & $\begin{array}{l}-0.072^{* * *} \\
(0.005)\end{array}$ & $\begin{array}{l}-0.069^{* * *} \\
(0.004)\end{array}$ & $\begin{array}{l}-0.072^{* * *} \\
(0.005)\end{array}$ & $\begin{array}{l}-0.070^{* * *} \\
(0.004)\end{array}$ \\
\hline$\rho\left(i_{n}, j, t-1\right)^{2}$ & $\begin{array}{l}0.000^{* *} \\
(0.000)\end{array}$ & $\begin{array}{l}0.000^{* * *} \\
(0.000)\end{array}$ & $\begin{array}{l}0.000^{* *} \\
(0.000)\end{array}$ & $\begin{array}{l}0.000^{* *} \\
(0.000)\end{array}$ & $\begin{array}{l}0.000^{* *} \\
(0.000)\end{array}$ & $\begin{array}{l}0.000^{* *} \\
(0.000)\end{array}$ \\
\hline
\end{tabular}




\begin{tabular}{|c|c|c|c|c|c|c|}
\hline GDP growth, yoy & $\begin{array}{c}-0.006 \\
(0.033)\end{array}$ & $\begin{array}{c}-0.772^{* * *} \\
(0.247)\end{array}$ & & & & \\
\hline Lag 1 quarters & $\begin{array}{c}-0.055 \\
(0.052)\end{array}$ & $\begin{array}{c}-0.604^{* * *} \\
(0.067)\end{array}$ & & & & \\
\hline Lag 2 quarters & $\begin{array}{l}0.134^{* *} \\
(0.056)\end{array}$ & $\begin{array}{l}0.890^{* * * *} \\
(0.133)\end{array}$ & & & & \\
\hline Lag 3 quarters & $\begin{array}{c}-0.037 \\
(0.050)\end{array}$ & $\begin{array}{c}-0.417^{* * *} \\
(0.154)\end{array}$ & & & & \\
\hline Lag 4 quarters & $\begin{array}{l}0.140^{* * *} \\
(0.032)\end{array}$ & $\begin{array}{l}0.517^{* * *} \\
(0.112)\end{array}$ & & & & \\
\hline RER index, gr. qoq & & & $\begin{array}{l}0.075^{* * *} \\
(0.014)\end{array}$ & $\begin{array}{l}0.223^{* * *} \\
(0.036)\end{array}$ & & \\
\hline Lag 1 quarters & & & $\begin{array}{l}0.098^{* * *} \\
(0.016)\end{array}$ & $\begin{array}{l}0.358^{* * * *} \\
(0.051)\end{array}$ & & \\
\hline Lag 2 quarters & & & $\begin{array}{c}0.027^{*} \\
(0.014)\end{array}$ & $\begin{array}{c}-0.033 \\
(0.038)\end{array}$ & & \\
\hline Lag 3 quarters & & & $\begin{array}{c}-0.049^{* * *} \\
(0.014)\end{array}$ & $\begin{array}{l}0.104^{* * * *} \\
(0.038)\end{array}$ & & \\
\hline Lag 4 quarters & & & $\begin{array}{c}-0.017 \\
(0.014)\end{array}$ & $\begin{array}{c}0.053 \\
(0.041)\end{array}$ & & \\
\hline 3m LIBOR, 1st diff. & & & & & $\begin{array}{c}-0.211^{* * *} \\
(0.060)\end{array}$ & $\begin{array}{l}0.271^{* * *} \\
(0.045)\end{array}$ \\
\hline Lag 1 quarters & & & & & $\begin{array}{c}-0.221^{* * *} \\
(0.055)\end{array}$ & $\begin{array}{c}-0.781^{* * *} \\
(0.117)\end{array}$ \\
\hline Lag 2 quarters & & & & & $\begin{array}{l}0.389^{* * *} \\
(0.081)\end{array}$ & $\begin{array}{c}-0.139 \\
(0.192)\end{array}$ \\
\hline Lag 3 quarters & & & & & $\begin{array}{l}0.362^{* * *} \\
(0.094)\end{array}$ & $\begin{array}{l}0.743^{* * *} \\
(0.233)\end{array}$ \\
\hline Lag 4 quarters & & & & & $\begin{array}{l}0.358^{* * *} \\
(0.066)\end{array}$ & $\begin{array}{l}0.838^{* * *} \\
(0.114) \\
\end{array}$ \\
\hline Pseudo $R^{2}$ & 0.196 & 0.211 & 0.195 & 0.209 & 0.196 & 0.202 \\
\hline Observations & 180,032 & 180,032 & 180,032 & 180,032 & 180,032 & 180,032 \\
\hline Panel B: Negative price changes & model1 & model1IV & model2 & model2IV & model3 & model3IV \\
\hline Rel. change VAT & $\begin{array}{c}-0.079 \\
(0.055)\end{array}$ & $\begin{array}{c}-0.132^{* *} \\
(0.065)\end{array}$ & $\begin{array}{c}-0.099^{* *} \\
(0.048)\end{array}$ & $\begin{array}{c}-0.096^{*} \\
(0.058)\end{array}$ & $\begin{array}{c}-0.104^{* *} \\
(0.049)\end{array}$ & $\begin{array}{c}-0.066 \\
(0.053)\end{array}$ \\
\hline Rel.chan. VAT, 1 Lag(s) & $\begin{array}{c}-0.278^{* * *} \\
(0.071)\end{array}$ & $\begin{array}{c}-0.309^{* * *} \\
(0.082)\end{array}$ & $\begin{array}{c}-0.273^{* * *} \\
(0.073)\end{array}$ & $\begin{array}{c}-0.297^{* * *} \\
(0.110)\end{array}$ & $\begin{array}{c}-0.248^{* * *} \\
(0.071)\end{array}$ & $\begin{array}{c}-0.264^{* * * *} \\
(0.098)\end{array}$ \\
\hline Rel.chan. VAT, 2 Lag(s) & $\begin{array}{c}-0.132^{* *} \\
(0.060)\end{array}$ & $\begin{array}{c}-0.074 \\
(0.081)\end{array}$ & $\begin{array}{c}-0.153^{* * *} \\
(0.058)\end{array}$ & $\begin{array}{c}-0.163^{* *} \\
(0.074)\end{array}$ & $\begin{array}{c}-0.141^{* *} \\
(0.059)\end{array}$ & $\begin{array}{c}-0.160^{* *} \\
(0.066)\end{array}$ \\
\hline Fut.VAT-incr. known, 1 Lag(s) & $\begin{array}{c}-0.067 \\
(0.050)\end{array}$ & $\begin{array}{c}-0.004 \\
(0.071)\end{array}$ & $\begin{array}{c}-0.079 \\
(0.057)\end{array}$ & $\begin{array}{c}-0.111 \\
(0.078)\end{array}$ & $\begin{array}{c}-0.084 \\
(0.054)\end{array}$ & $\begin{array}{c}-0.079 \\
(0.058)\end{array}$ \\
\hline
\end{tabular}


Fut.VAT-incr. known, 2 Lag(s)

Fut.VAT-incr. known, 3 Lag(s)

Fut.VAT-incr. known, 4 Lag(s)

Fut.VAT-incr. known, 5 Lag(s)

Periods since last price change, $z\left(i_{n}, j, t,\right)$

$z\left(i_{n}, j, t,\right)^{2}$

Dummy 1st quarter

Dummy 2nd quarter

Dummy 3rd quarter

Sales

Sales end

Dummy 2000Q2

Acc.sec.infl., $\pi\left(i_{n}, j, t\right)$

Price relative to mean price, $\rho\left(i_{n}, j, t-1\right)$

$\rho\left(i_{n}, j, t-1\right)^{2}$

GDP growth, yoy

Lag 1 quarters

Lag 2 quarters

Lag 3 quarters

Lag 4 quarters

RER index, gr. qoq

\begin{tabular}{|c|c|c|c|c|c|}
\hline $\begin{array}{c}-0.156^{* *} \\
(0.062)\end{array}$ & $\begin{array}{c}-0.189^{* *} \\
(0.076)\end{array}$ & $\begin{array}{c}-0.147^{* *} \\
(0.065)\end{array}$ & $\begin{array}{c}-0.144 \\
(0.091)\end{array}$ & $\begin{array}{c}-0.135^{* *} \\
(0.064)\end{array}$ & $\begin{array}{c}-0.083 \\
(0.075)\end{array}$ \\
\hline-0.074 & -0.072 & -0.092 & -0.106 & $\begin{array}{l}-0.090 \\
(0.060)\end{array}$ & -0.083 \\
\hline$(0.059)$ & $(0.067)$ & $(0.058)$ & $(0.087)$ & $(0.060)$ & $(0.061)$ \\
\hline$-0.228^{* *}$ & -0.214 & $-0.234^{* *}$ & -0.223 & $-0.225^{*}$ & -0.233 \\
\hline$(0.113)$ & $(0.274)$ & $(0.113)$ & $(0.225)$ & $(0.115)$ & $(0.211)$ \\
\hline 0.317 & 1.606 & 0.077 & 0.074 & -0.714 & -1.470 \\
\hline$(0.801)$ & (1.669) & $(0.756)$ & $(0.808)$ & $(1.055)$ & $(1.303)$ \\
\hline 0.021 & 0.030 & 0.032 & 0.037 & 0.018 & 0.019 \\
\hline$(0.026)$ & $(0.028)$ & $(0.026)$ & $(0.031)$ & $(0.026)$ & $(0.029)$ \\
\hline $0.001^{* *}$ & $0.001^{* *}$ & $0.001^{* *}$ & $0.001^{* *}$ & $0.002^{* *}$ & $0.002^{* *}$ \\
\hline$(0.001)$ & $(0.001)$ & $(0.001)$ & $(0.001)$ & $(0.001)$ & $(0.001)$ \\
\hline $0.271^{* *}$ & $0.356^{* * *}$ & $0.252^{* *}$ & 0.222 & $0.258^{* *}$ & 0.131 \\
\hline$(0.109)$ & $(0.122)$ & $(0.117)$ & $(0.151)$ & $(0.106)$ & $(0.129)$ \\
\hline $0.204^{* *}$ & $0.306^{* *}$ & $0.187^{*}$ & $0.206^{*}$ & $0.201^{* *}$ & 0.177 \\
\hline$(0.100)$ & $(0.133)$ & $(0.099)$ & $(0.108)$ & $(0.102)$ & $(0.109)$ \\
\hline 0.128 & 0.226 & 0.124 & 0.099 & 0.068 & 0.021 \\
\hline$(0.108)$ & $(0.168)$ & $(0.120)$ & $(0.141)$ & $(0.117)$ & $(0.140)$ \\
\hline $24.964^{* * *}$ & $22.255^{* * *}$ & $24.984^{* * *}$ & $22.191^{* * *}$ & $23.995^{* * *}$ & $22.074^{* * *}$ \\
\hline$(0.402)$ & $(2.767)$ & $(0.399)$ & $(2.954)$ & $(0.455)$ & $(2.904)$ \\
\hline $1.859^{*}$ & 1.855 & $1.868^{*}$ & 1.896 & $1.821^{*}$ & 1.846 \\
\hline$(1.052)$ & $(4.591)$ & (1.047) & $(4.887)$ & (1.065) & $(4.862)$ \\
\hline $1.784^{* * *}$ & $1.600^{* * *}$ & $1.948^{* * *}$ & $2.024^{* * *}$ & $1.568^{* * *}$ & $1.473^{* * *}$ \\
\hline$(0.286)$ & $(0.397)$ & $(0.247)$ & $(0.298)$ & $(0.258)$ & $(0.388)$ \\
\hline 0.005 & -0.010 & -0.020 & -0.027 & 0.010 & 0.011 \\
\hline$(0.048)$ & $(0.057)$ & $(0.048)$ & $(0.062)$ & $(0.047)$ & $(0.057)$ \\
\hline $0.125^{* * *}$ & $0.125^{* * *}$ & $0.125^{* * *}$ & $0.126^{* * *}$ & $0.125^{* * *}$ & $0.125^{* * *}$ \\
\hline$(0.009)$ & $(0.009)$ & $(0.009)$ & $(0.010)$ & $(0.009)$ & $(0.009)$ \\
\hline$-0.001^{* * *}$ & $-0.001^{* * *}$ & $-0.001^{* * *}$ & $-0.001^{* * *}$ & $-0.001^{* * *}$ & $-0.001^{* * *}$ \\
\hline$(0.000)$ & $(0.000)$ & $(0.000)$ & $(0.000)$ & $(0.000)$ & $(0.000)$ \\
\hline 0.047 & -0.198 & & & & \\
\hline$(0.056)$ & $(0.286)$ & & & & \\
\hline-0.060 & $-0.163^{* *}$ & & & & \\
\hline$(0.082)$ & $(0.078)$ & & & & \\
\hline 0.059 & $0.330^{*}$ & & & & \\
\hline$(0.086)$ & $(0.190)$ & & & & \\
\hline-0.009 & -0.215 & & & & \\
\hline$(0.092)$ & $(0.190)$ & & & & \\
\hline-0.007 & 0.113 & & & & \\
\hline \multirow{2}{*}{$(0.055)$} & $(0.127)$ & & & & \\
\hline & & -0.003 & 0.019 & & \\
\hline
\end{tabular}




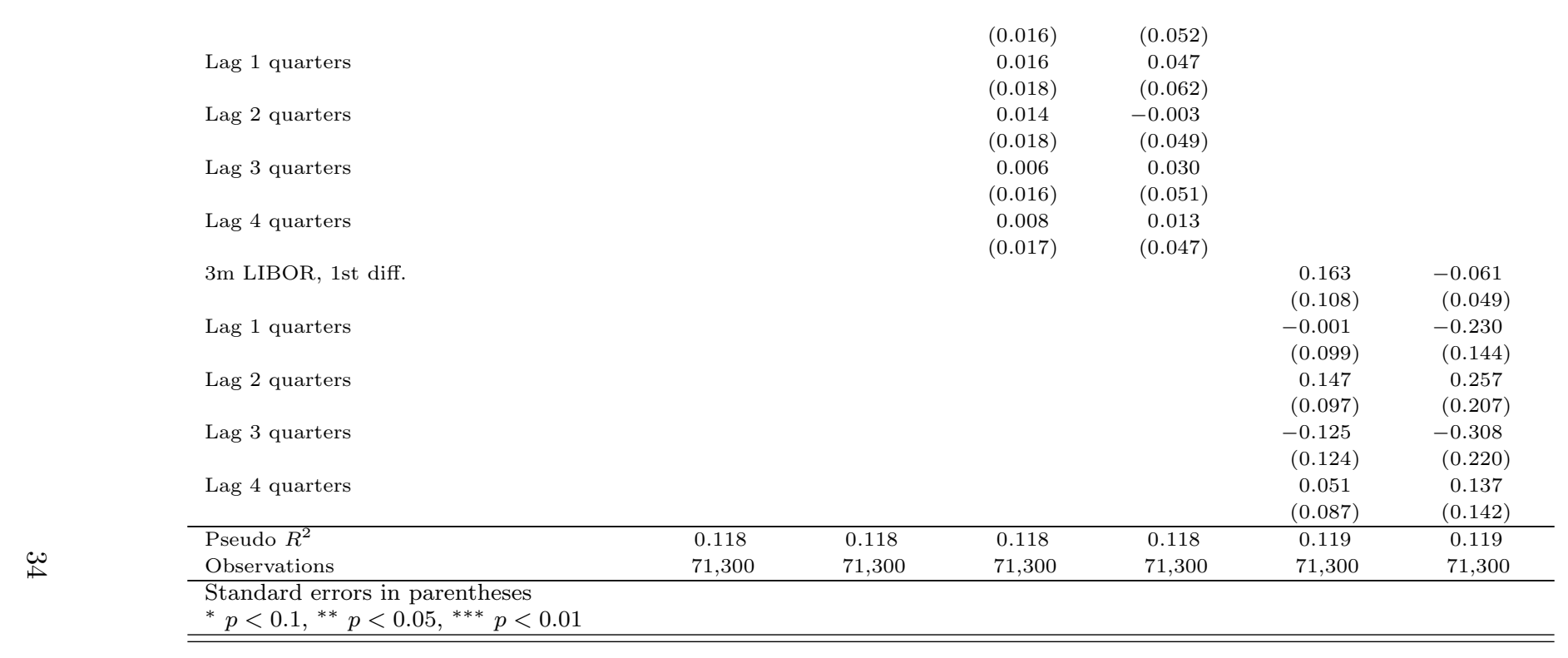




\section{B. Additional robustness checks}

\section{B.1. Reduced time frame}

The following tables show the estimation results using a shorted time frame (i.e., 1996Q1-2012Q4).

Table B.9: Estimation results with restricted time frame: Size of relative price change

\begin{tabular}{|c|c|c|c|}
\hline & Specification 1 & Specification 2 & Specification 3 \\
\hline Rel. change VAT & $\begin{array}{l}1.696^{* * *} \\
(0.213)\end{array}$ & $\begin{array}{l}1.877^{* * *} \\
(0.214)\end{array}$ & $\begin{array}{l}1.700^{* * *} \\
(0.211)\end{array}$ \\
\hline Rel.chan. VAT, 1 Lag(s) & $\begin{array}{c}-0.145^{* *} \\
(0.069)\end{array}$ & $\begin{array}{c}0.026 \\
(0.071)\end{array}$ & $\begin{array}{c}0.000 \\
(0.088)\end{array}$ \\
\hline Rel.chan. VAT, 2 Lag(s) & $\begin{array}{l}0.302^{* *} \\
(0.121)\end{array}$ & $\begin{array}{l}0.472^{* * *} \\
(0.117)\end{array}$ & $\begin{array}{l}0.478^{* * *} \\
(0.128)\end{array}$ \\
\hline Fut.VAT-incr. known, 1 Lag(s) & $\begin{array}{r}-0.135^{*} \\
(0.072)\end{array}$ & $\begin{array}{c}0.033 \\
(0.073)\end{array}$ & $\begin{array}{r}-0.154^{*} \\
(0.083)\end{array}$ \\
\hline Fut.VAT-incr. known, 2 Lag(s) & $\begin{array}{c}0.013 \\
(0.083)\end{array}$ & $\begin{array}{r}0.155^{*} \\
(0.084)\end{array}$ & $\begin{array}{l}0.316^{* * *} \\
(0.095)\end{array}$ \\
\hline Fut.VAT-incr. known, 3 Lag(s) & $\begin{array}{l}-0.312^{* * *} \\
(0.069)\end{array}$ & $\begin{array}{l}-0.171^{* *} \\
(0.073)\end{array}$ & $\begin{array}{c}0.125 \\
(0.103)\end{array}$ \\
\hline Fut.VAT-incr. known, 4 Lag(s) & $\begin{array}{l}-0.755^{* * *} \\
(0.255)\end{array}$ & $\begin{array}{l}-0.697^{* * *} \\
(0.255)\end{array}$ & $\begin{array}{r}-0.539 \\
(0.413)\end{array}$ \\
\hline Fut.VAT-incr. known, 5 Lag(s) & $\begin{array}{r}-0.077 \\
(0.251)\end{array}$ & $\begin{array}{c}-0.234 \\
(0.238)\end{array}$ & $\begin{array}{r}-0.563 \\
(0.425)\end{array}$ \\
\hline Periods since last price change, $z\left(i_{n}, j, t,\right)$ & $\begin{array}{l}0.047^{* * *} \\
(0.004)\end{array}$ & $\begin{array}{l}0.033^{* * *} \\
(0.005)\end{array}$ & $\begin{array}{l}0.027^{* * *} \\
(0.006)\end{array}$ \\
\hline$z\left(i_{n}, j, t,\right)^{2}$ & $\begin{array}{l}-0.000^{* * *} \\
(0.000)\end{array}$ & $\begin{array}{l}-0.001^{* * *} \\
(0.000)\end{array}$ & $\begin{array}{l}-0.001^{* * *} \\
(0.000)\end{array}$ \\
\hline Dummy 1st quarter & $\begin{array}{l}0.346^{* * *} \\
(0.037)\end{array}$ & $\begin{array}{l}0.355^{* * *} \\
(0.036)\end{array}$ & $\begin{array}{l}0.359^{* * *} \\
(0.044)\end{array}$ \\
\hline Dummy 2nd quarter & $\begin{array}{l}0.198^{* * *} \\
(0.038)\end{array}$ & $\begin{array}{l}0.159^{* * *} \\
(0.037)\end{array}$ & $\begin{array}{l}0.185^{* * *} \\
(0.046)\end{array}$ \\
\hline Dummy 3rd quarter & $\begin{array}{c}0.009 \\
(0.028)\end{array}$ & $\begin{array}{c}-0.020 \\
(0.027)\end{array}$ & $\begin{array}{c}-0.007 \\
(0.036)\end{array}$ \\
\hline Sales & $\begin{array}{c}-18.795^{* * *} \\
(2.223)\end{array}$ & $\begin{array}{c}-18.264^{* * *} \\
(2.213)\end{array}$ & $\begin{array}{c}-18.228^{* * *} \\
(2.236)\end{array}$ \\
\hline Sales end & $\begin{array}{l}16.304^{* * *} \\
(5.741)\end{array}$ & $\begin{array}{l}15.384^{* * *} \\
(5.581)\end{array}$ & $\begin{array}{l}15.384^{* * *} \\
(5.567)\end{array}$ \\
\hline Dummy 2000Q2 & $\begin{array}{c}0.229 \\
(0.330)\end{array}$ & $\begin{array}{c}0.472 \\
(0.321)\end{array}$ & $\begin{array}{l}0.668^{* *} \\
(0.327)\end{array}$ \\
\hline Acc.sec.infl., $\pi\left(i_{n}, j, t\right)$ & & $\begin{array}{c}-0.044^{* * *} \\
(0.014)\end{array}$ & $\begin{array}{c}-0.023 \\
(0.014)\end{array}$ \\
\hline Price relative to mean price, $\rho\left(i_{n}, j, t-1\right)$ & & $\begin{array}{l}-0.099^{* * *} \\
(0.005)\end{array}$ & $\begin{array}{l}-0.099^{* * *} \\
(0.005)\end{array}$ \\
\hline$\rho\left(i_{n}, j, t-1\right)^{2}$ & & $\begin{array}{l}0.000^{* * *} \\
(0.000)\end{array}$ & $\begin{array}{l}0.000^{* * *} \\
(0.000)\end{array}$ \\
\hline GDP growth, yoy & & & $\begin{array}{c}0.001 \\
(0.019)\end{array}$ \\
\hline Lag 1 quarters & & & $\begin{array}{c}0.018 \\
(0.027)\end{array}$ \\
\hline Lag 2 quarters & & & $\begin{array}{r}-0.053^{*} \\
(0.030)\end{array}$ \\
\hline Lag 3 quarters & & & $\begin{array}{c}0.008 \\
(0.034)\end{array}$ \\
\hline Lag 4 quarters & & & $\begin{array}{l}0.091^{* * *} \\
(0.020)\end{array}$ \\
\hline RER index, gr. qoq & & & $\begin{array}{l}0.028^{* * *} \\
(0.008)\end{array}$ \\
\hline
\end{tabular}




\begin{tabular}{|c|c|c|c|}
\hline Lag 1 quarters & & & $\begin{array}{l}0.030^{* * *} \\
(0.008)\end{array}$ \\
\hline Lag 2 quarters & & & $\begin{array}{c}-0.019^{* *} \\
(0.008)\end{array}$ \\
\hline Lag 3 quarters & & & $\begin{array}{c}-0.026^{* * *} \\
(0.006)\end{array}$ \\
\hline Lag 4 quarters & & & $\begin{array}{c}-0.028^{* * *} \\
(0.008)\end{array}$ \\
\hline 3m LIBOR, 1st diff. & & & $\begin{array}{c}-0.080^{*} \\
(0.041)\end{array}$ \\
\hline Lag 1 quarters & & & $\begin{array}{c}0.024 \\
(0.042)\end{array}$ \\
\hline Lag 2 quarters & & & $\begin{array}{c}0.013 \\
(0.049)\end{array}$ \\
\hline Lag 3 quarters & & & $\begin{array}{c}-0.100^{*} \\
(0.055)\end{array}$ \\
\hline Lag 4 quarters & & & $\begin{array}{c}-0.059 \\
(0.046)\end{array}$ \\
\hline Constant & $\begin{array}{c}-0.142^{* * *} \\
(0.034)\end{array}$ & $\begin{array}{c}-0.190^{* * *} \\
(0.057)\end{array}$ & $\begin{array}{c}-0.304^{* * *} \\
(0.073)\end{array}$ \\
\hline Adjusted $R^{2}$ & 0.028 & 0.065 & 0.067 \\
\hline $\begin{array}{l}\text { Observations } \\
\text { Standard errors in parentheses } \\
{ }^{*} p<0.1,{ }^{* *} p<0.05,{ }^{* * *} p<0.01\end{array}$ & 198,989 & 198,989 & 198,989 \\
\hline
\end{tabular}

Table B.10: Cond. logit probability model with restricted time frame.

\begin{tabular}{|c|c|c|c|}
\hline Panel A: Positive price changes & Specification 1 & Specification 2 & Specification 3 \\
\hline \multirow[t]{2}{*}{ Rel. change VAT } & $1.868^{* * *}$ & $2.214^{* * *}$ & $1.636^{* * *}$ \\
\hline & $(0.141)$ & $(0.156)$ & $(0.193)$ \\
\hline \multirow[t]{2}{*}{ Rel.chan. VAT, 1 Lag(s) } & $-0.925^{* * *}$ & $-0.821^{* *}$ & $-1.154^{* * *}$ \\
\hline & $(0.310)$ & $(0.325)$ & $(0.415)$ \\
\hline \multirow[t]{2}{*}{ Rel.chan. VAT, 2 Lag(s) } & $0.923^{* * *}$ & $1.097^{* * *}$ & $0.987^{* * *}$ \\
\hline & $(0.245)$ & $(0.256)$ & $(0.312)$ \\
\hline \multirow[t]{2}{*}{ Fut.VAT-incr. known, 1 Lag(s) } & -0.617 & -0.366 & $-0.924^{* *}$ \\
\hline & $(0.405)$ & $(0.413)$ & $(0.417)$ \\
\hline \multirow[t]{2}{*}{ Fut.VAT-incr. known, 2 Lag(s) } & 0.260 & $0.518^{* *}$ & $0.875^{* * *}$ \\
\hline & $(0.246)$ & $(0.257)$ & $(0.271)$ \\
\hline \multirow[t]{2}{*}{ Fut.VAT-incr. known, 3 Lag(s) } & $-1.078^{* * *}$ & $-0.859^{* *}$ & -0.011 \\
\hline & $(0.341)$ & $(0.353)$ & $(0.391)$ \\
\hline \multirow[t]{2}{*}{ Fut.VAT-incr. known, 4 Lag(s) } & $-1.672^{* * *}$ & $-1.625^{* * *}$ & -1.366 \\
\hline & $(0.515)$ & $(0.504)$ & $(0.963)$ \\
\hline \multirow[t]{2}{*}{ Fut.VAT-incr. known, 5 Lag(s) } & -0.109 & -0.244 & -0.590 \\
\hline & $(0.605)$ & $(0.600)$ & $(1.078)$ \\
\hline \multirow[t]{2}{*}{ Periods since last price change, $z\left(i_{n}, j, t,\right)$} & $0.114^{* * *}$ & $0.079^{* * *}$ & $0.089^{* * *}$ \\
\hline & $(0.011)$ & $(0.014)$ & $(0.014)$ \\
\hline \multirow[t]{2}{*}{$z\left(i_{n}, j, t,\right)^{2}$} & $-0.001^{* *}$ & $-0.001^{* * *}$ & $-0.001^{* * *}$ \\
\hline & $(0.000)$ & $(0.000)$ & $(0.000)$ \\
\hline \multirow[t]{2}{*}{ Dummy 1st quarter } & $1.130^{* * *}$ & $1.156^{* * *}$ & $1.067^{* * *}$ \\
\hline & $(0.103)$ & $(0.104)$ & $(0.118)$ \\
\hline \multirow[t]{2}{*}{ Dummy 2nd quarter } & $0.665^{* * *}$ & $0.630^{* * *}$ & $0.566^{* * *}$ \\
\hline & $(0.101)$ & $(0.100)$ & $(0.121)$ \\
\hline \multirow[t]{2}{*}{ Dummy 3rd quarter } & -0.031 & -0.064 & -0.029 \\
\hline & $(0.090)$ & $(0.091)$ & $(0.105)$ \\
\hline \multirow[t]{2}{*}{ Sales } & $-13.830^{* * *}$ & $-13.919^{* * *}$ & $-13.818^{* * *}$ \\
\hline & $(0.481)$ & $(0.521)$ & $(0.483)$ \\
\hline \multirow[t]{3}{*}{ Sales end } & $3.272^{* * *}$ & $2.817^{* * *}$ & $2.823^{* * *}$ \\
\hline & $(0.572)$ & $(0.544)$ & $(0.502)$ \\
\hline & 36 & & \\
\hline
\end{tabular}


Dummy 2000Q2

Acc.sec.infl., $\pi\left(i_{n}, j, t\right)$

Price relative to mean price, $\rho\left(i_{n}, j, t-1\right)$

$\rho\left(i_{n}, j, t-1\right)^{2}$

GDP growth, yoy

Lag 1 quarters

Lag 2 quarters

Lag 3 quarters

Lag 4 quarters

RER index, gr. qoq

Lag 1 quarters

Lag 2 quarters

Lag 3 quarters

Lag 4 quarters

3m LIBOR, 1st diff.

Lag 1 quarters

Lag 2 quarters

Lag 3 quarters

Lag 4 quarters
$0.869^{* * *}$

(0.149)

$1.073^{* *}$
$(0.158)$
$0.070^{* *}$
$(0.035)$
$-0.078^{* * *}$
$(0.005)$
$0.000^{* *}$
$(0.000)$
$1.377^{* * *}$

(0.214)

$0.062^{*}$

(0.034)

$-0.081^{* * *}$

(0.005)

$0.000^{* *}$

(0.000)

0.006

(0.044)

0.040

(0.070)

$-0.085$

(0.066)

$-0.200^{* * *}$

(0.077)

$0.275^{* * *}$

(0.052)

$0.095^{* * *}$

(0.016)

$0.103^{* * *}$

(0.020)

0.016

(0.018)

$-0.024$

(0.017)

$-0.031^{*}$

(0.018)

$-0.214^{* *}$

(0.108)

0.067

(0.115)

$0.388^{* * *}$

(0.106)

0.170

(0.129)

0.108

(0.134)

0.169

\begin{tabular}{lrrr}
\hline Pseudo $R^{2}$ & 0.127 & 0.153 & 0.169 \\
Observations & 158,057 & 158,057 & 158,057
\end{tabular}

\begin{tabular}{lccc}
\hline Panel B: Negative price changes & Specification 1 & Specification 2 & Specification 3 \\
\hline Rel. change VAT & $0.636^{* * *}$ & $0.445^{* *}$ & 0.299 \\
& $(0.207)$ & $(0.217)$ & $(0.253)$ \\
Rel.chan. VAT, 1 Lag(s) & $-1.389^{* * *}$ & $-1.382^{* * *}$ & $-1.521^{* * *}$ \\
& $(0.396)$ & $(0.390)$ & $(0.450)$ \\
Rel.chan. VAT, 2 Lag(s) & 0.366 & 0.277 & 0.134 \\
& $(0.273)$ & $(0.265)$ & $(0.302)$ \\
Fut.VAT-incr. known, 1 Lag(s) & $-1.198^{* * *}$ & $-1.337^{* * *}$ & $-1.452^{* * *}$ \\
& $(0.340)$ & $(0.327)$ & $(0.393)$ \\
Fut.VAT-incr. known, 2 Lag(s) & 0.339 & 0.208 & 0.168 \\
& $(0.363)$ & $(0.361)$ & $(0.412)$ \\
Fut.VAT-incr. known, 3 Lag(s) & -0.192 & -0.302 & -0.535 \\
& $(0.397)$ & $(0.389)$ & $(0.439)$ \\
Fut.VAT-incr. known, 4 Lag(s) & -0.912 & -0.690 & -1.456 \\
Fut.VAT-incr. known, 5 Lag(s) & $(0.657)$ & $(0.706)$ & $(1.294)$ \\
Periods since last price change, $z\left(i_{n}, j, t,\right)$ & -0.393 & -0.174 & -1.074 \\
& $(0.749)$ & $(0.765)$ & $(1.170)$ \\
$z\left(i_{n}, j, t,\right)^{2}$ & -0.015 & 0.031 & 0.036 \\
& $(0.019)$ & $(0.027)$ & $(0.027)$
\end{tabular}


Dummy 1st quarter

Dummy 2nd quarter

Dummy 3rd quarter

Sales

Sales end

Dummy 2000Q2

Acc.sec.infl., $\pi\left(i_{n}, j, t\right)$

Price relative to mean price, $\rho\left(i_{n}, j, t-1\right)$

$\rho\left(i_{n}, j, t-1\right)^{2}$

GDP growth, yoy

Lag 1 quarters

Lag 2 quarters

Lag 3 quarters

Lag 4 quarters

RER index, gr. qoq

Lag 1 quarters

Lag 2 quarters

Lag 3 quarters

Lag 4 quarters

3m LIBOR, 1st diff

Lag 1 quarters

Lag 2 quarters

Lag 3 quarters

Lag 4 quarters

\begin{tabular}{|c|c|c|}
\hline$(0.001)$ & $(0.001)$ & $(0.001)$ \\
\hline 0.187 & 0.131 & 0.138 \\
\hline$(0.120)$ & $(0.120)$ & $(0.135)$ \\
\hline 0.168 & $0.172^{*}$ & $0.213^{*}$ \\
\hline$(0.106)$ & $(0.101)$ & $(0.112)$ \\
\hline-0.043 & -0.034 & -0.040 \\
\hline$(0.121)$ & $(0.119)$ & $(0.135)$ \\
\hline $18.449^{* * *}$ & $24.144^{* * *}$ & $23.560^{* * *}$ \\
\hline$(0.348)$ & $(0.411)$ & $(0.465)$ \\
\hline 1.190 & $1.753^{*}$ & 1.743 \\
\hline$(0.891)$ & (1.056) & (1.077) \\
\hline $1.986^{* * *}$ & $1.838^{* * *}$ & $1.442^{* * *}$ \\
\hline \multirow[t]{37}{*}{$(0.237)$} & $(0.247)$ & $(0.305)$ \\
\hline & -0.029 & -0.043 \\
\hline & $(0.049)$ & $(0.053)$ \\
\hline & $0.126^{* * *}$ & $0.127^{* * *}$ \\
\hline & $(0.009)$ & $(0.009)$ \\
\hline & $-0.001^{* * *}$ & $-0.001^{* * *}$ \\
\hline & $(0.000)$ & $(0.000)$ \\
\hline & & 0.002 \\
\hline & & $(0.073)$ \\
\hline & & -0.037 \\
\hline & & $(0.088)$ \\
\hline & & 0.024 \\
\hline & & $(0.090)$ \\
\hline & & -0.114 \\
\hline & & $(0.100)$ \\
\hline & & 0.021 \\
\hline & & $(0.065)$ \\
\hline & & 0.009 \\
\hline & & $(0.019)$ \\
\hline & & $0.043^{* *}$ \\
\hline & & $(0.020)$ \\
\hline & & $0.045^{* *}$ \\
\hline & & $(0.020)$ \\
\hline & & 0.034 \\
\hline & & $(0.022)$ \\
\hline & & 0.018 \\
\hline & & $(0.023)$ \\
\hline & & 0.220 \\
\hline & & $(0.161)$ \\
\hline & & 0.183 \\
\hline & & $(0.132)$ \\
\hline & & $0.320^{* *}$ \\
\hline & & $(0.162)$ \\
\hline & & 0.079 \\
\hline & & $(0.183)$ \\
\hline & & 0.119 \\
\hline & & $(0.160)$ \\
\hline 0.040 & 0.125 & 0.128 \\
\hline 65,010 & 65,010 & 65,010 \\
\hline
\end{tabular}

Pseudo $R^{2}$

Observations

65,010

65,010

Standard errors in parentheses

${ }^{*} p<0.1,{ }^{* *} p<0.05,{ }^{* * *} p<0.01$ 


\section{B.2. Results with censored data}

The following tables present the estimation results for a modified dataset, where we have assumed $k_{1}\left(i_{n}, j\right) \equiv t_{1} \forall i, j$, i.e., the first datapoint of each price series is considered as a price change.

Table B.11: Estimation results with censored data: Size of relative price change

\begin{tabular}{|c|c|c|c|}
\hline & Specification 1 & Specification 2 & Specification 3 \\
\hline \multirow[t]{2}{*}{ Rel. change VAT } & $1.075^{* * *}$ & $1.065^{* * *}$ & $1.057^{* * *}$ \\
\hline & $(0.041)$ & $(0.040)$ & $(0.043)$ \\
\hline \multirow[t]{2}{*}{ Rel.chan. VAT, 1 Lag(s) } & $0.072^{* * *}$ & $0.048^{* * *}$ & 0.027 \\
\hline & $(0.019)$ & $(0.017)$ & $(0.021)$ \\
\hline \multirow[t]{2}{*}{ Rel.chan. VAT, 2 Lag(s) } & $0.042^{* * *}$ & $0.020^{* *}$ & 0.020 \\
\hline & $(0.008)$ & $(0.009)$ & $(0.013)$ \\
\hline \multirow[t]{2}{*}{ Fut.VAT-incr. known, 1 Lag(s) } & $0.101^{* * *}$ & $0.098^{* * *}$ & $0.097^{* * *}$ \\
\hline & $(0.019)$ & $(0.019)$ & $(0.021)$ \\
\hline \multirow[t]{2}{*}{ Fut.VAT-incr. known, 2 Lag(s) } & $0.068^{* * *}$ & $0.065^{* * *}$ & $0.097^{* * *}$ \\
\hline & $(0.015)$ & $(0.015)$ & $(0.018)$ \\
\hline \multirow[t]{2}{*}{ Fut.VAT-incr. known, 3 Lag(s) } & $0.050^{* * *}$ & $0.045^{* * *}$ & $0.095^{* * *}$ \\
\hline & $(0.015)$ & $(0.015)$ & $(0.017)$ \\
\hline \multirow[t]{2}{*}{ Fut.VAT-incr. known, 4 Lag(s) } & $0.088^{* * *}$ & $0.069^{* * *}$ & $0.069^{* * *}$ \\
\hline & $(0.018)$ & $(0.017)$ & $(0.019)$ \\
\hline \multirow[t]{2}{*}{ Fut.VAT-incr. known, 5 Lag(s) } & -0.169 & $-0.442^{*}$ & -0.379 \\
\hline & $(0.235)$ & $(0.228)$ & $(0.425)$ \\
\hline \multirow[t]{2}{*}{ Periods since last price change, $z\left(i_{n}, j, t,\right)$} & $0.047^{* * *}$ & $0.010^{* *}$ & 0.001 \\
\hline & $(0.004)$ & $(0.004)$ & $(0.005)$ \\
\hline \multirow{2}{*}{$z\left(i_{n}, j, t,\right)^{2}$} & $-0.001^{* * *}$ & $-0.001^{* * *}$ & $-0.001^{* * *}$ \\
\hline & $(0.000)$ & $(0.000)$ & $(0.000)$ \\
\hline \multirow[t]{2}{*}{ Dummy 1st quarter } & $0.351^{* * *}$ & $0.383^{* * *}$ & $0.407^{* * *}$ \\
\hline & $(0.036)$ & $(0.034)$ & $(0.038)$ \\
\hline \multirow[t]{2}{*}{ Dummy 2nd quarter } & $0.135^{* * *}$ & $0.113^{* * *}$ & $0.199^{* * *}$ \\
\hline & $(0.032)$ & $(0.031)$ & $(0.037)$ \\
\hline \multirow[t]{2}{*}{ Dummy 3rd quarter } & -0.001 & -0.010 & $0.061^{* *}$ \\
\hline & $(0.026)$ & $(0.025)$ & $(0.030)$ \\
\hline \multirow[t]{2}{*}{ Sales } & $-19.252^{* * *}$ & $-18.862^{* * *}$ & $-18.833^{* * *}$ \\
\hline & $(2.353)$ & $(2.380)$ & $(2.435)$ \\
\hline \multirow[t]{2}{*}{ Sales end } & $16.681^{* * *}$ & $15.623^{* * *}$ & $15.662^{* * *}$ \\
\hline & $(5.844)$ & $(5.640)$ & $(5.638)$ \\
\hline \multirow[t]{2}{*}{ Dummy 2000Q2 } & $0.739^{*}$ & $0.977^{* *}$ & $1.069^{* *}$ \\
\hline & $(0.430)$ & $(0.419)$ & $(0.429)$ \\
\hline \multirow[t]{2}{*}{ Acc.sec.infl., $\pi\left(i_{n}, j, t\right)$} & & $0.038^{* * *}$ & $0.063^{* * *}$ \\
\hline & & $(0.011)$ & $(0.011)$ \\
\hline \multirow[t]{2}{*}{ Price relative to mean price, $\rho\left(i_{n}, j, t-1\right)$} & & $-0.099^{* * *}$ & $-0.099^{* * *}$ \\
\hline & & $(0.005)$ & $(0.005)$ \\
\hline \multirow{2}{*}{$\rho\left(i_{n}, j, t-1\right)^{2}$} & & $0.000^{* * *}$ & $0.000^{* * *}$ \\
\hline & & $(0.000)$ & $(0.000)$ \\
\hline \multirow[t]{2}{*}{ GDP growth, yoy } & & & $0.034^{*}$ \\
\hline & & & $(0.017)$ \\
\hline \multirow[t]{2}{*}{ Lag 1 quarters } & & & -0.025 \\
\hline & & & $(0.028)$ \\
\hline Lag 2 quarters & & & 0.000 \\
\hline & & & $(0.030)$ \\
\hline Lag 3 quarters & & & -0.000 \\
\hline & & & $(0.026)$ \\
\hline Lag 4 quarters & & & $0.115^{* * *}$ \\
\hline & & & $(0.014)$ \\
\hline RER index, gr. qoq & & & $0.034^{* * *}$ \\
\hline & & & $(0.007)$ \\
\hline Lag 1 quarters & & & $0.022^{* * *}$ \\
\hline
\end{tabular}




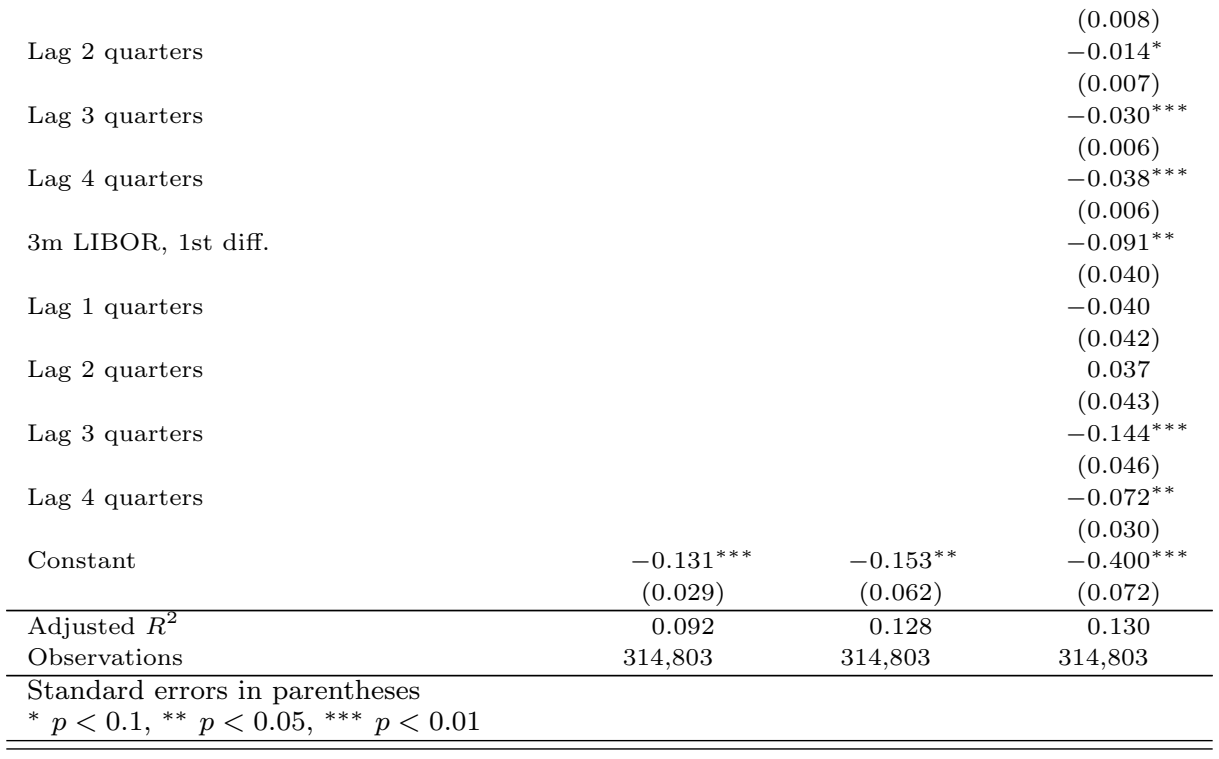

Table B.12: Cond. logit probability model with censored data.

\begin{tabular}{lccc}
\hline \hline Panel A: Positive price changes & Specification 1 & Specification 2 & Specification 3 \\
\hline Rel. change VAT & $0.633^{* * *}$ & $0.630^{* * *}$ & $0.537^{* * *}$ \\
& $(0.025)$ & $(0.027)$ & $(0.037)$ \\
Rel.chan. VAT, 1 Lag(s) & $0.123^{* * *}$ & $0.073^{*}$ & 0.003 \\
& $(0.044)$ & $(0.039)$ & $(0.043)$ \\
Rel.chan. VAT, 2 Lag(s) & 0.068 & 0.029 & -0.042 \\
& $(0.044)$ & $(0.044)$ & $(0.049)$ \\
Fut.VAT-incr. known, 1 Lag(s) & $0.265^{* * *}$ & $0.245^{* * *}$ & $0.250^{* * *}$ \\
& $(0.033)$ & $(0.033)$ & $(0.044)$ \\
Fut.VAT-incr. known, 2 Lag(s) & $0.167^{* * *}$ & $0.147^{* * *}$ & $0.204^{* * *}$ \\
& $(0.040)$ & $(0.040)$ & $(0.044)$ \\
Fut.VAT-incr. known, 3 Lag(s) & $0.095^{* *}$ & $0.074^{*}$ & $0.161^{* * *}$ \\
& $(0.040)$ & $(0.039)$ & $(0.041)$ \\
Fut.VAT-incr. known, 4 Lag(s) & $0.143^{* * *}$ & $0.103^{* * *}$ & $0.118^{* * *}$ \\
& $(0.028)$ & $(0.028)$ & $(0.035)$ \\
Fut.VAT-incr. known, 5 Lag(s) & -0.042 & -0.254 & 0.210 \\
& $(0.591)$ & $(0.590)$ & $(1.011)$ \\
Periods since last price change, $z\left(i_{n}, j, t,\right)$ & $0.120^{* * *}$ & $0.072^{* * *}$ & $0.062^{* * *}$ \\
$z\left(i_{n}, j, t,\right)^{2}$ & $(0.009)$ & $(0.011)$ & $(0.010)$ \\
& $-0.001^{* * *}$ & $-0.002^{* * *}$ & $-0.002^{* * *}$ \\
Dummy 1st quarter & $(0.000)$ & $(0.000)$ & $(0.000)$ \\
& $1.228^{* * *}$ & $1.290^{* * *}$ & $1.251^{* * *}$ \\
Dummy 2nd quarter & $(0.087)$ & $(0.087)$ & $(0.098)$ \\
& $0.551^{* * *}$ & $0.537^{* * *}$ & $0.566^{* * *}$ \\
Dummy 3rd quarter & $(0.093)$ & $(0.092)$ & $(0.104)$ \\
& 0.103 & 0.094 & $0.239^{* * *}$ \\
Sales & $(0.083)$ & $(0.083)$ & $(0.089)$ \\
Sales end & $-14.721^{* * *}$ & $-13.797^{* * *}$ & $-13.645^{* * *}$ \\
Dummy 2000Q2 & $(0.487)$ & $(0.508)$ & $(0.415)$ \\
& $3.381^{* * *}$ & $2.807^{* * *}$ & $2.949^{* * *}$ \\
& $(0.605)$ & $(0.531)$ & $(0.500)$ \\
& $0.854^{* * *}$ & $1.045^{* * *}$ & $1.163^{* * *}$ \\
& & &
\end{tabular}


Acc.sec.infl., $\pi\left(i_{n}, j, t\right)$

Price relative to mean price, $\rho\left(i_{n}, j, t-1\right)$

$\rho\left(i_{n}, j, t-1\right)^{2}$

GDP growth, yoy

Lag 1 quarters

Lag 2 quarters

Lag 3 quarters

Lag 4 quarters

RER index, gr. qoq

Lag 1 quarters

Lag 2 quarters

Lag 3 quarters

Lag 4 quarters

3m LIBOR, 1st diff.

Lag 1 quarters

Lag 2 quarters

Lag 3 quarters

Lag 4 quarters

Pseudo $R^{2}$

Observations

Panel B: Negative price changes

Rel. change VAT

Rel.chan. VAT, 1 Lag(s)

Rel.chan. VAT, 2 Lag(s)

Fut.VAT-incr. known, 1 Lag(s)

Fut.VAT-incr. known, 2 Lag(s)

Fut.VAT-incr. known, 3 Lag(s)

Fut.VAT-incr. known, 4 Lag(s)

Fut.VAT-incr. known, 5 Lag(s)

Periods since last price change, $z\left(i_{n}, j, t,\right)$

$z\left(i_{n}, j, t,\right)^{2}$
$(0.147)$

\begin{tabular}{|c|c|}
\hline$(0.149)$ & $(0.192)$ \\
\hline $0.128^{* * *}$ & $0.178^{* * *}$ \\
\hline$(0.025)$ & $(0.026)$ \\
\hline$-0.071^{* * *}$ & $-0.072^{* * *}$ \\
\hline$(0.004)$ & $(0.004)$ \\
\hline $0.000^{* *}$ & $0.000^{* *}$ \\
\hline$(0.000)$ & $(0.000)$ \\
\hline & 0.048 \\
\hline & $(0.039)$ \\
\hline & -0.030 \\
\hline & $(0.066)$ \\
\hline & 0.030 \\
\hline & $(0.064)$ \\
\hline & $-0.175^{* * *}$ \\
\hline & $(0.060)$ \\
\hline & $0.291^{* * *}$ \\
\hline & $(0.036)$ \\
\hline & $0.098^{* * *}$ \\
\hline & $(0.014)$ \\
\hline & $0.099^{* * *}$ \\
\hline & $(0.017)$ \\
\hline & 0.013 \\
\hline & $(0.018)$ \\
\hline & $-0.043^{* * *}$ \\
\hline & $(0.016)$ \\
\hline & $-0.039^{* *}$ \\
\hline & $(0.016)$ \\
\hline & -0.105 \\
\hline & $(0.092)$ \\
\hline & $-0.171^{*}$ \\
\hline & $(0.099)$ \\
\hline & $0.367^{* * *}$ \\
\hline & $(0.088)$ \\
\hline & 0.006 \\
\hline & $(0.111)$ \\
\hline & 0.048 \\
\hline & $(0.087)$ \\
\hline 0.216 & 0.238 \\
\hline 70,384 & 270,384 \\
\hline
\end{tabular}

270,384

270,384

270,384

$\begin{array}{ccc}\text { Specification } 1 & \text { Specification } 2 & \text { Specification 3 } \\ -0.010 & -0.055 & -0.116^{* *} \\ (0.032) & (0.033) & (0.052) \\ -0.184^{* * *} & -0.209^{* * *} & -0.275^{* * *} \\ (0.065) & (0.067) & (0.070) \\ -0.080 & -0.104^{* *} & -0.147^{* * *} \\ (0.050) & (0.052) & (0.057) \\ -0.026 & -0.071^{* *} & -0.105^{* *} \\ (0.033) & (0.036) & (0.046) \\ -0.116^{*} & -0.182^{* * *} & -0.236^{* * *} \\ (0.060) & (0.060) & (0.064) \\ -0.013 & -0.091^{* *} & -0.135^{* * *} \\ (0.034) & (0.035) & (0.045) \\ -0.107^{* *} & -0.179^{* * *} & -0.198^{* * *} \\ (0.045) & (0.048) & (0.052) \\ -0.201 & 0.248 & -0.536 \\ (0.709) & (0.734) & (1.060) \\ -0.002 & 0.026 & 0.021 \\ (0.017) & (0.021) & (0.020) \\ 0.001^{*} & 0.001^{* *} & 0.001^{* *} \\ (0.001) & (0.001) & (0.001)\end{array}$




\begin{tabular}{|c|c|c|c|}
\hline Dummy 1st quarter & $\begin{array}{l}0.320^{* * *} \\
(0.099)\end{array}$ & $\begin{array}{l}0.339^{* * *} \\
(0.102)\end{array}$ & $\begin{array}{l}0.311^{* * *} \\
(0.110)\end{array}$ \\
\hline Dummy 2nd quarter & $\begin{array}{r}0.170^{*} \\
(0.093)\end{array}$ & $\begin{array}{l}0.242^{* *} \\
(0.095)\end{array}$ & $\begin{array}{l}0.234^{* *} \\
(0.101)\end{array}$ \\
\hline Dummy 3rd quarter & $\begin{array}{c}0.113 \\
(0.104)\end{array}$ & $\begin{array}{c}0.171 \\
(0.108)\end{array}$ & $\begin{array}{c}0.109 \\
(0.117)\end{array}$ \\
\hline Sales & $\begin{array}{l}20.507^{* * *} \\
(0.343)\end{array}$ & $\begin{array}{l}25.528^{* * *} \\
(0.356)\end{array}$ & $\begin{array}{l}24.654^{* * *} \\
(0.404)\end{array}$ \\
\hline Sales end & $\begin{array}{c}1.392 \\
(0.881)\end{array}$ & $\begin{array}{l}2.212^{* *} \\
(1.029)\end{array}$ & $\begin{array}{l}2.176^{* *} \\
(1.052)\end{array}$ \\
\hline Dummy 2000Q2 & $\begin{array}{l}2.043^{* * *} \\
(0.215)\end{array}$ & $\begin{array}{l}1.881^{* * *} \\
(0.220)\end{array}$ & $\begin{array}{l}1.286^{* * *} \\
(0.268)\end{array}$ \\
\hline Acc.sec.infl., $\pi\left(i_{n}, j, t\right)$ & & $\begin{array}{c}0.027 \\
(0.036)\end{array}$ & $\begin{array}{c}0.034 \\
(0.036)\end{array}$ \\
\hline Price relative to mean price, $\rho\left(i_{n}, j, t-1\right)$ & & $\begin{array}{l}0.120^{* * *} \\
(0.008)\end{array}$ & $\begin{array}{l}0.122^{* * *} \\
(0.008)\end{array}$ \\
\hline$\rho\left(i_{n}, j, t-1\right)^{2}$ & & $\begin{array}{l}-0.001^{* * *} \\
(0.000)\end{array}$ & $\begin{array}{l}-0.001^{* * *} \\
(0.000)\end{array}$ \\
\hline GDP growth, yoy & & & $\begin{array}{c}0.017 \\
(0.065)\end{array}$ \\
\hline Lag 1 quarters & & & $\begin{array}{c}-0.108 \\
(0.079)\end{array}$ \\
\hline Lag 2 quarters & & & $\begin{array}{c}0.081 \\
(0.082)\end{array}$ \\
\hline Lag 3 quarters & & & $\begin{array}{c}-0.120 \\
(0.082)\end{array}$ \\
\hline Lag 4 quarters & & & $\begin{array}{c}-0.011 \\
(0.053)\end{array}$ \\
\hline RER index, gr. qoq & & & $\begin{array}{l}0.017 \\
(0.017)\end{array}$ \\
\hline Lag 1 quarters & & & $\begin{array}{l}0.040^{* *} \\
(0.020)\end{array}$ \\
\hline Lag 2 quarters & & & $\begin{array}{c}0.037^{*} \\
(0.021)\end{array}$ \\
\hline Lag 3 quarters & & & $\begin{array}{c}0.034^{*} \\
(0.019)\end{array}$ \\
\hline Lag 4 quarters & & & $\begin{array}{l}0.016 \\
(0.021)\end{array}$ \\
\hline 3m LIBOR, 1st diff. & & & $\begin{array}{c}0.328^{* *} \\
(0.156)\end{array}$ \\
\hline Lag 1 quarters & & & $\begin{array}{c}0.138 \\
(0.125)\end{array}$ \\
\hline Lag 2 quarters & & & $\begin{array}{l}0.344^{* *} \\
(0.134)\end{array}$ \\
\hline Lag 3 quarters & & & $\begin{array}{c}0.134 \\
(0.141)\end{array}$ \\
\hline Lag 4 quarters & & & $\begin{array}{c}0.221^{* *} \\
(0.096)\end{array}$ \\
\hline Pseudo $R^{2}$ & 0.034 & 0.118 & 0.122 \\
\hline Observations & 96,446 & 96,446 & 96,446 \\
\hline
\end{tabular}

